\title{
Is generalised cost justified in travel demand analysis?
}

\author{
Mark Wardman ${ }^{1,2} \cdot$ Jeremy Toner $^{2}$
}

Published online: 14 February 2018

(C) The Author(s) 2018. This article is an open access publication

\begin{abstract}
Generalised cost (GC) has long been widely used as a measure of the attractiveness of travel alternatives. We argue that its limitations have been forgotten, overlooked or not appreciated, and it is used because 'it has always been used'. We explore the relationships between GC and its components (price, time, value of time) and their respective demand elasticities and show that the variation of component elasticities over time and space is not consistent with the variation implied by a GC formulation. We therefore conduct detailed tests of whether the GC approach is justified. The datasets used are recorded ticket sales between pairs of railway stations for a number of years and covering a variety of types of flow. When restricted to a GC formulation, we find that allowing VoT to be estimated as part of the modelling process is greatly superior to using either the UK official VoTs or using VoTs from meta-analyses. We conclude that the importance of using the correct VoT in calculating GC cannot be overstated. Failure to do so will lead to incorrect derivation of component elasticities from the GC elasticity. A more flexible approach estimating elasticities to components of GC is better than even the best GC formulation. We conclude that robust models, with large sample sizes and very precise coefficient estimates in their standard form, are not able to support the variation in GJT and fare elasticities that would be implied by the GC approach. It might be time to stop using GC.
\end{abstract}

Keywords Generalised cost · Travel demand modelling · Elasticity · Value of time

Mark Wardman

mwardman@systra.com

1 SYSTRA, Manchester, UK

2 Institute for Transport Studies, University of Leeds, Leeds, UK 


\section{Introduction}

\section{The issues}

Transport planners the world over make much use of generalised cost (GC) and/or generalised time (GT) which represent the overall attractiveness of a travel alternative in equivalent units of money or travel time. This is because such composite terms have a number of attractions at both the estimation and application stages. These include overcoming estimation problems due to co-linearity between or lack of variation in the constituent variables, ${ }^{1}$ introducing the potentially desirable feature that the elasticities to the constituent variables depend upon the proportion they form of the composite term, supporting a consistent approach to forecasting and economic appraisal, reducing concerns about the use of constituent elasticities for large proportionate changes, and avoiding the problems in consumer surplus measurement where a constituent variable, such as fare under a concessionary scheme, is zero. Searle (1978) justified its use on the grounds that "it results in better practice than its more simple alternatives" and that "we [should not] overlook the commonsense virtues of generalised cost".

Nonetheless, one possible reason why GC is used is because 'it has always been used', and we here contend that its potential limitations have been forgotten, overlooked or indeed not appreciated. This paper not only raises the question of whether the use of GC in demand models is justified but provides some empirically based answers. Bruzelius (1981) contends that the "articles (Grey 1978a, b; Goodwin 1978; Searle 1978) demonstrate that there is a considerable lack of understanding in the profession". We contend that this is still the case with regard to GC.

Although the GC formulation is widely adopted, it imposes properties without any explicit testing of whether they are empirically justified. This has long been recognised (Jones 1977; Grey 1978a). Indeed, Grey (1978a) stated that, "The principal restriction is that the ratio of the rates of change of demand $\mathrm{Q}$ with respect to any two independent variables $C_{i}, C_{j}$ is not fixed directly by empirical evidence, but by the predetermined generalised cost specification". The GC approach forces the implied constituent elasticities to exhibit large cross-sectional variations according to the make-up of GC on different journeys and an increase (reduction) in time (cost) related elasticities, all other things equal, as monetary values increase over time with income growth. ${ }^{2}$ Moreover, it is implicitly assumed that the value of time used in appraisal can be taken to be appropriate for demand forecasting.

A different approach, and one used by the rail industry in Great Britain, is to merge the time related aspects (journey time, frequency and interchange) ${ }^{3}$ into a single variable, termed generalised journey time (GJT), but to maintain fare as a separate term. We term this the GJT-Fare approach. This approach also forces elasticity variation, given that the elasticities of the component variables of GJT will vary with the proportion that they form

\footnotetext{
${ }^{1}$ For example, the GC approach has attractions where, as is often the case in the car and bus markets, there is sufficient evidence on price elasticities but a dearth of evidence on time elasticities (TRL et al. 2004).

2 There is also what Gunn (1983) termed "a crucial ambiguity" that models expressed in terms of GC (GT) will imply a reduction (increase) in demand over time as the value of time increases with income. We do not here address this issue but rather focus our attention on the use of GC (GT) in the elasticity domain.

3 The wait time element common in GC calculations is taken up by the frequency term. Walk time is also a common feature of GC but not in the rail demand models which form the evidence base here since they are estimated to recorded demand between stations.
} 
of GJT. Whilst this might not be justified, and indeed was addressed in Wardman (1994), the formulation of the GJT function is not the focus of this paper.

Finally, what might be regarded as the conventional economics approach would be to enter into the demand model separately each of the key attributes regarded to influence demand. We term this the separate components (SC) approach. We note that it invariably characterises the very extensive discrete choice modelling literature. The SC approach is here covered to demonstrate the potential for further disaggregation of the components of GJT, and for reference and interest given that we can estimate it, but its most appropriate formulation is not the focus of this paper.

\section{The opportunity and aims}

The railway industry in Great Britain has available very large amounts of ticket sales data which provide a reasonably accurate account of rail travel between very many stations over numerous years. Whilst rail fares exhibit variation over time, just as the costs of other modes do, a key attraction is that rail routes can also exhibit variations in the timetable related service quality attributes of journey time, frequency and interchange. This then supports modelling opportunities not otherwise possible which we here exploit to test a number of important hypotheses. As Bruzelius (1981), summarising Searle (1978), concluded: "the use of generalised cost has to be based on [the claim that] travel demand functions in terms of generalised costs seem to be working better than other types of travel demand models". Specifically, the aims of the research reported here are to test:

- whether the GC approach of standard transport planning provides a better explanation of rail travel demand than the standard rail industry GJT and fare approach or indeed an approach that specifies separate elasticities to each component of GC;

- whether the elasticities to GJT and fare implied by the GC approach can be empirically justified;

- whether variations over time and across routes in the GJT and fare elasticities implied by the GC formulation are empirically justified;

- the appropriate values of time to adopt conditional upon the use of the GC approach.

In short, is generalised cost justified in travel demand analysis?

\section{Scope and significance}

The research findings here discussed are both original and significant because, as far as we aware, there has been no explicit and detailed testing of the 'hypotheses' set out in "The opportunity and aims" section along with GC being a dominant formulation worldwide where transport planning and appraisal is practised. It is important to know whether GC is empirically valid because of the fact that GC is consistent with conventional microeconomic demand theory if and only if the willingness to pay to save travel time is not a function of real income (Bruzelius 1981). In addition to insights of a methodological nature, we also provide a range of results that are of broader interest for the purposes of forecasting, benchmarking and interpretation in the passenger rail market.

In terms of the scope of the research reported here, which is primarily concerned with the validity of the GC approach, we make a number of important points largely stemming from its originality. We aim to understand these fundamentals of GC as currently used in practice but with a view to developing this investigation to address more complex issues. 
Firstly, we have not considered 'flexible' functional forms where the GC, GJT and SC formulations might through appropriate parameterisation approximate each other. The analysis reported here is couched very much in the tradition of these approaches, that is, characterised by constant elasticities to GC, GJT and Fare, and the SC variables. The analysis of more flexible functions is a separate study in its own right.

Secondly, the analysis could have been extended to the direct estimation of a wider range of weights used in the composite GJT terms. We are though of the view that this would not materially add to or alter the findings presented here. Again, this is a separate study beyond the scope of the significant issues this paper aims to address.

Thirdly, and related to the previous point, our focus here is on comparing the GC and GJT-Fare approaches on the grounds that the latter is dominant in the rail industry in Britain and serves as a sound empirical basis to test the former whereas the robust estimation of each of the SC elements to provide a firm basis of comparison is a much more challenging task.

Finally, we have not addressed dynamic behavioural responses. In part, this is because two of the three data sets available to us cover only a few years. But more importantly, the analysis of dynamic effects would cloud our investigations and add an element of complexity in terms of the relationships explored that would not contribute to answering the important hypotheses set out in "The opportunity and aims" section.

\section{Structure}

The structure of the paper is as follows. "The candidate model formulations" section provides background discussion covering the competing demand model formulations. "What insights on expected elasticity variation are provided by existing evidence?" section considers the insights that are provided by review study evidence into the elasticity variation here being examined whilst the rail ticket sales data used in our analysis are described in "Data used in analysis" section. "Model specification" section sets out the candidate models to be evaluated and examines whether fixed or random effects models are more appropriate to our investigations. The main empirical findings and tests of hypotheses are contained in "Empirical findings" section and concluding remarks are provided in "Conclusions" section.

\section{The candidate model formulations}

\section{The GC approach ${ }^{4}$}

The concept of GC has been widely used in transport planning since the late 1960s (Goodwin 1978). Indeed, Searle (1978) claimed that, “...... what could be more sensible as a simple working hypothesis than to assume that major determinants of travel behaviour are a linear combination of time and money cost parameters?" McIntosh and Quarmby (1970) first set out the procedures recommended for use in transport planning studies in Britain but the term seems to originate with Wilson (1969).

Despite the widespread use of GC, review studies (TRRL 1980; Goodwin 1992; Balcombe et al. 2004; ATOC 2013; Wardman 2014) all point to there being extensive

\footnotetext{
${ }^{4}$ We take this to be the conventional formulation where GC is a linear-additive combination of its component parts.
} 
evidence relating to fare elasticities but surprisingly little for GC elasticities. ${ }^{5}$ Indeed the $\mathrm{GC}$ elasticity is sometimes deduced from the much more common evidence on price elasticities.

We can compose GC in this rail context simply as the summation of fare (F) and generalised journey time (GJT):

$$
G C=F+\mu G J T
$$

GJT represents the timetable related service quality in time units, as discussed in "The GJT and fare approach" section, and $\mu$ is the money value of time that converts GJT into an equivalent monetary amount. The value of $\mu$ is invariably pre-specified, but as we shall see it can here be directly estimated.

If we specify the relationship between the volume of rail demand (V) and GC in typical constant elasticity form:

$$
V=\kappa G C^{\lambda} \ldots \ldots
$$

then the implied elasticities ( $\eta$ ) to GJT and fare are:

$$
\begin{array}{r}
\eta_{G J T}=\lambda \frac{\mu G J T}{G C} \\
\eta_{F}=\lambda \frac{F}{G C}
\end{array}
$$

The elasticity to a constituent variable is the product of the proportion that it forms of GC and the GC elasticity $(\lambda)$. Since GT is simply a change from money to time units, the GT and GC elasticity are the same and the implied GJT and fare elasticities are unaffected. The sum of the constituent elasticities equals the component elasticity. Note also that functional relationships between demand and GC other than Eq. 2 still impose the property that the component elasticities depend upon the proportion that they form of GC.

The implied GJT and fare elasticities will exhibit strong variation across routes according to the proportion that each variable forms of GC and, since $\mu$ will increase over time with income, the implied GJT (fare) elasticity will be forced to increase (fall) over time, all other things equal. Whilst these are not a priori unreasonable properties, as far as we are aware they have not been subjected to explicit empirical testing. ${ }^{6}$ In addition, GC is invariably calculated using the best available evidence on the value of time rather than upon a directly estimated value of time that provides the best explanation of demand conditional upon the use of GC.

The GC approach implies that the value of time is:

$$
\mu=\frac{F}{G J T} \frac{\eta_{G J T}}{\eta_{F}}
$$

\footnotetext{
5 It is surprising why there is so little evidence on GC elasticities when GC is so widely used in forecasting.

6 Indeed, our experience is that when rail demand models are allowed to depart from the standard constant elasticity position the alternative is either rarely empirically preferable or else, with flexible functional forms, the estimated elasticity variation is slight.
} 
We subsequently make use of this relationship although, more usefully where there is limited evidence on one of the elasticities, its re-arrangement allows $\eta_{\text {GJT }}\left(\eta_{F}\right)$ to be deduced if we have evidence on $\eta_{\mathrm{F}}\left(\eta_{\mathrm{GJT}}\right)$ and $\mu$. $^{7}$ So, for example:

$$
\eta_{G J T}=\mu \frac{G J T}{F} \eta_{F}
$$

\section{The GJT and fare approach}

With a pedigree almost as long as the GC approach is the UK rail industry's practice of using separate fare and GJT terms. This is set out in the Passenger Demand Forecasting Handbook (PDFH) which is unique worldwide amongst railway organisations and indeed transport authorities in general. It has set out a recommended forecasting procedure and associated parameters since 1986 (ATOC 2013). ${ }^{8}$ GJT stemmed from the need for an index to represent the timetable related attractiveness of train services which have somewhat different journey times, departure time profiles and interchange requirements across the day (Tyler and Hassard 1973). The different British Rail computer systems dealing with timetables and revenue led to a separation of GJT and fare which has persisted to this day without any empirical testing of whether movement to the conventional GC approach or indeed the SC approach would provide a better forecasting approach.

There is a considerable evidence base covering GJT and fare elasticities in the rail industry in Great Britain, as is clear from PDFH and large-scale reviews of the literature (Wardman 2012, 2014).

PDFH specifies the demand function in conventional constant elasticity form as:

$$
V=v G J T^{\delta} F^{\gamma} \ldots \ldots
$$

GJT is constituted as:

$$
G J T=S T+\tau H+\omega I
$$

ST is the station-to-station journey time including any interchange connection time. ${ }^{9}$ The frequency penalty $(\tau)$ and interchange penalty $(\omega)$ convert service headway $(H)$ and the number of interchanges (I) into equivalent journey time. Whilst GJT could, in principle, be enhanced with other terms, such as travel time reliability, rolling stock and crowding levels, their inclusion in the time-series models that provide the evidence base is fraught with serious problems such as the lack of historical evidence, the lack of variation over time and difficulties of measurement.

The estimation of the GJT elasticity $(\delta)$ has almost always been based on the 'best' prior evidence relating to $\tau$ and $\omega$ to construct GJT. The few exceptions are Wardman and Whelan (2004) and Wheat and Wardman (2017) who simultaneously estimated $\tau, \omega$ and $\delta$.

\footnotetext{
7 For example, the TRL et al. (2004) review of public transport demand elasticities uses this relationship to provide deduced time-based elasticities in the bus market where there is a dearth of directly estimated evidence. Of course, the elasticities to other terms within GJT can also be deduced.

8 The initial PDFH was issued in 1986 and the most recent update (v6) was undertaken in 2017. Updates on the original were 1989 (v2), 1997 (v3), 2002 (v4), 2005 (v4.1), 2009 (v5) and 2013 (v5.1).

9 The standard formulation of GJT in PDFH remains station-to-station journey time even though it has been possible for many years to isolate connection time in the industry model that supplies the GJT data. All GJT models reported in this paper do not isolate the connection time component of station-to-station time.
} 
Whilst this GJT-Fare approach is more flexible than the GC approach, it still forces the elasticities to time, headway and interchange to depend upon the proportion that each forms of GJT. ${ }^{10}$

\section{The SC approach}

The conventional (Marshallian) demand models of economic theory and practice typically relate the volume of demand to distinct terms such as time, cost, frequency and interchange. But in addition an extensive discrete choice literature has developed over the same period as GC's existence and central to the latter is the composite utility term that reflects the attractiveness of an alternative. Whilst this could itself be made a function of a created $\mathrm{GC}$, this is never done and instead the key travel attributes enter separately. ${ }^{11}$

For the variables of interest here, the conventional constant elasticity SC demand model specification would be:

$$
V=\phi S T^{\alpha} H^{\beta} e^{\psi I} F^{\gamma} \ldots \ldots
$$

Interchange takes this form because it is discrete and often zero, and the parameter $\psi$ denotes the constant proportionate change in demand after a change in the number of interchanges. If connection time is separated from ST, as it is in some of our reported SC models, then it also enters in the same form as interchange, albeit in minutes rather than as the number of interchanges, given that it can be zero.

\section{What insights on expected elasticity variation are provided by existing evidence?}

Whilst we contend that there have been no studies that have tested the GC approach to the degree that is reported below, available evidence might still be able to shed light on the validity of the GC model's elasticity properties.

The GC approach implies that there will be considerable variation in GJT and fare elasticities over time and across routes. Our experience from analysing rail demand and conducting review studies over the past 30 years is that it is often difficult to discern statistically significant variations in GJT and fare elasticities that overturn constant elasticity models, let alone ones that approach those implied by the GC approach. Notwithstanding our impressions and experiences, a much firmer empirical basis is provided by drawing upon the insights provided by three major reviews and meta-analyses of UK evidence.

Wardman (2014) covers 1633 price elasticities for car, rail and bus drawn from 167 studies published between 1968 and 2010. Wardman (2012) covers the period 1977-2010 and 209 (rail) GJT elasticities and 168 IVT elasticities. Abrantes and Wardman (2011) cover 1749 valuations between 1960 and 2008 including 933 IVT values, 29 car congested time values and 39 car free flow values.

\footnotetext{
${ }^{10}$ Nonetheless, this separation of GJT and fare, as advocated by Jones (1977), would overcome Gunn's "crucial ambiguity" units problem when using either GC or GT in forecasting over time.

11 These choice models have their own untested properties, such as the elasticities being very strongly influenced by market share.
} 
Table 1 Summary evidence from meta-analysis studies

\begin{tabular}{|c|c|c|c|c|}
\hline & Price elasticity & GJT elasticity & IVT elasticity & Value of time \\
\hline \multicolumn{5}{|c|}{ Inter-temporal income effects } \\
\hline Rail & None & None & None & 0.90 income elasticity \\
\hline $\begin{array}{l}\text { Other } \\
\text { modes }\end{array}$ & None & n.a. & None & 0.90 income elasticity \\
\hline \multicolumn{5}{|c|}{ Distance effects } \\
\hline Rail & $\begin{array}{l}-7 \% \text { inter-urban non } \\
\text { London }\end{array}$ & $\begin{array}{l}0.20 \text { distance } \\
\text { elasticity }\end{array}$ & $\begin{array}{l}0.25 \text { distance } \\
\text { elasticity }\end{array}$ & 0.16 distance elasticity \\
\hline $\begin{array}{l}\text { Other } \\
\text { modes }\end{array}$ & $\begin{array}{l}+77 \% \text { inter-urban car } \\
+26 \% \text { inter-urban bus }\end{array}$ & n.a. & $\begin{array}{l}+78 \% \text { inter- } \\
\text { urban car } \\
+131 \% \text { inter- } \\
\text { urban bus }\end{array}$ & $\begin{array}{l}0.21 \text { distance elasticity car } \\
0.16 \text { distance elasticity bus }\end{array}$ \\
\hline \multicolumn{5}{|c|}{ Purpose effects } \\
\hline Rail & $\begin{array}{l}-44 \% \text { business, }+ \\
31 \% \text { leisure }\end{array}$ & $\begin{array}{l}+14 \% \\
\text { commute }\end{array}$ & $\begin{array}{r}+14 \% \text { for } \\
\text { commute }\end{array}$ & $\begin{array}{l}+113 \% \text { business, }+12 \% \\
\text { commute }\end{array}$ \\
\hline $\begin{array}{l}\text { Other } \\
\text { modes }\end{array}$ & $\begin{array}{l}-44 \% \text { business, } \\
+31 \% \text { leisure }\end{array}$ & n.a. & $\begin{array}{r}+14 \% \text { for } \\
\text { commute }\end{array}$ & $\begin{array}{l}+113 \% \text { business, }+12 \% \\
\text { commute }\end{array}$ \\
\hline
\end{tabular}

GJT elasticity evidence relates only to rail

The evidence from these major meta-analyses can be used in conjunction with Eq. 6 to provide insights as to whether the empirical relationships between the time elasticity, price elasticity and value of time support the GC approach.

The relevant insights from these meta-analyses are summarised in Table 1 for the key variables of income growth over time, journey distance and journey purpose. We distinguish rail from other modes given that this paper analyses rail data and that rail provides substantial proportions of the meta-analysis evidence. The elasticity terms in Table 1 indicate how the value of time varies with income or how an elasticity varies with distance. So the distance elasticity for IVT for rail indicates that a $10 \%$ increase in distance would increase the IVT elasticity by $2.5 \%$. The other terms denote proportionate effects on a parameter.

Income is a very important variable given that the value of time increases with it over time and hence the balance between the GJT and fare elasticities implied by the GC approach would be expected to vary with income growth, all else equal. However, all else is not equal, and the ratio GJT/F might vary over time. We subsequently analyse a data set covering the period 1995-2005 and over that period the GJT/F ratio fell by around $10 \%$ or $1 \%$ per annum, being broadly similar across the different types of flow covered. Given an elasticity of the value of time with respect to income of 0.9 , the value of time would have increased by around $2 \%$ per annum over that period for rail. Hence we might expect the elasticity of the GJT elasticity with respect to income to be larger than the corresponding fare elasticity variation. This is not the case.

Turning to car, real money costs have increased over time but so have journey times due to greater congestion. Over the period 1995-2014, inspection of National Travel Survey data (Leigh Fisher et al. 2016) implied that the ratio of time to cost was falling by around $1 \frac{1}{2} \%$ per annum. This contrasts with $2 \%$ value of time growth per annum and hence is not entirely consistent with the GC approach given the absence of income effects on the time and price elasticities. 
As for bus travel, fares have increased over time but then speeds have also deteriorated. The net effect would be expected to dampen but not remove the effect of the value of time growth within Eq. 6 whereby time elasticities should become more important than price elasticities over time but this is not the case.

With regard to journey distance, it is not clear how the GJT/F ratio for rail might be expected to vary. Whilst fares taper with distance, longer distance journeys are often faster and service frequency does not deteriorate in line with distance. Inspecting our 1995-2005 data sets, we regressed the logarithm of GJT/F on the logarithm of miles which provides elasticities which can conveniently be compared with the value of time distance elasticity of 0.16 reported in Table 1 . The estimated elasticity of GJT/F to miles was -0.16 for Non London flows and -0.10 for London flows. Thus the variations in GJT/F and the value of time in Eq. 6 essentially cancel out, implying that the time and fare elasticities should exhibit similar variation with respect to distance. However, we find that the rail time elasticities increase with distance quite strongly whereas there is a slight reduction on some flows for the price elasticity.

With respect to bus travel, speeds are higher for longer distance journeys and fares tend to taper. The balance between time and fare might though be fairly constant with distance. The value of time increases with distance for bus, the fare elasticity is larger for inter-urban trips and the IVT elasticity is somewhat larger for inter-urban trips. We might then conclude that the distance effects for bus are in line with what would be implied by the GC approach.

For car travel, speeds are higher for longer distances but fuel efficiency is also better. The balance between time and cost might not vary much with distance. The evidence points to time and cost elasticities being similarly larger for inter-urban trips, but given the quite strong distance elasticity on the value of time for car then the GC approach would imply a somewhat greater increase in the time elasticity than the cost elasticity with distance.

As for the other main variable of journey purpose, the key variations relate to business travel. The value of time for business travellers is essentially twice that of other travellers and the price elasticity is just over half that of commuters and around $60 \%$ less than leisure travellers. The variations in the value of time and fare elasticity essentially cancel out in Eq. 6 and so, given that there were no variations in time elasticities by purpose, consistency with the GC approach requires that the balance between time and cost is similar between business and other trips. This can be expected to be the case for car but we would expect GJT/F to be somewhat lower for rail business travellers given that they purchase more expensive tickets to travel first class or at peak times.

Whilst there are inevitable approximations and assumptions involved in using Eq. 6 and review evidence to test the relationships implied by the GC approach, we conclude that this consideration of existing empirical evidence at the very least indicates that the new primary research reported here into the validity of the GC approach is clearly warranted. It is to this that we now turn.

\section{Data used in analysis}

The data used here is recorded tickets sales between pairs of railway stations. In Great Britain, this has since the 1970s supported empirical analysis of how a wide range of factors impact on the demand for rail travel. 


\section{Elasticity estimation requirements}

The ability to estimate credible and precise elasticities is fundamental to the hypotheses here being tested. Drawing firm conclusions from comparisons of elasticities implied by the GC approach with those directly estimated using the GJT and Fare approach would clearly be hampered if the elasticity estimates were not plausible or possessed very large confidence intervals. Although not a primary requirement of our investigation, a desirable feature is that we can obtain reliable elasticity estimates for the component variables of GJT.

\section{The ticket sales data used}

Given that the issues we are here investigating are fundamental aspects of transport planning and forecasting, we have made use of the three datasets at our disposal which support our investigation in terms of being able to provide reliable GJT and fare elasticities. Within these data sets, we distinguish flow types which the rail industry in Great Britain customarily regard to be different and for which PDFH provides separate recommendations. Whilst this coverage of a range of datasets and flow types inevitably leads to an element of repetition, we feel that it is important to bring as much evidence to bear given the significance of the hypotheses we are testing and to determine whether our conclusions apply across a range of contexts.

Although rail has a significant presence in commuting markets in Great Britain, season ticket data is often unsuitable because the widespread use of area-wide 'travelcard' tickets in major urban areas means that we do not have an accurate account of travel between specific pairs of stations. In addition, key commuter flows tend to exhibit relatively little by way of GJT variation and fares are regulated.

\section{Annual data for non-London non season tickets 2006-2010}

This data was assembled for a project with the primary objective of examining the impact of large changes in timetable related service quality on rail demand (Wheat and Wardman 2017). Flows were selected where timetable changes had brought about an increase or reduction in GJT of at least $20 \%$ at some time in the period 2006-2010. This yielded 274 flows on Non-London long distance ${ }^{12}$ routes. The monetary variables are all expressed in 2006 prices. The timetable related service quality data distinguishes train in-vehicle time, service frequency, the number of interchanges and any connection time.

\section{Annual data for long distance non-season tickets 1996-2001}

This data set was assembled for the specific purpose of examining the influence on rail demand of changes in timetable related service quality (Wardman and Whelan 2004). It covers 138 inter-urban London flows and 594 Non London inter-urban flows. All monetary terms are in 2001 prices. The timetable related service quality data distinguishes train invehicle time, service frequency, the number of interchanges and any connection time.

$\overline{12}$ In Britain, the railways define long distance to be over 20 miles $(32 \mathrm{~km})$. 


\section{Annual data for non-season tickets 1995-2005}

This data was provided in order to examine the effects of external factors on rail demand (Wardman and Dargay 2007). Nonetheless, it turned out to be 'fit for purpose' in terms of being able to recover precise and reasonable elasticities to fare and GJT. It covers 621 long distance London flows, 2442 long distance Non London flows, 738 Non London short distance flows not entirely within travelcard areas and 686 flows within the South East of England around London but not entirely within the London Travelcard Area. The monetary variables are expressed in 2005 prices. The timetable related service quality data covers station-to-station journey time, without any distinction between in-vehicle time and connection time, along with service frequency and the number of interchanges.

\section{Summary of data analysed}

Table 2 summarises the data we have used in testing the hypotheses set out in "The opportunity and aims" section. We have removed flows to and from airports as atypical. The largest removal of observations was for long distance London flows covering the years 1995-2005. Models estimated to the full data set failed to recover sensible GJT and fare elasticities and this was attributed to volatility in demand on some minor flows. We removed 149 flows where in any year demand was less than 5 return trips per day which then enabled sensible results to be obtained. Note that whilst this reduces the number of flows by $24 \%$, the number of recorded journeys is reduced by less than $1 \%$. Excepting this flow type, it is clear from Table 2 that the modelled data is the vast majority of the available data.

Table 2 Available data-flow types, years and omissions

\begin{tabular}{|c|c|c|c|c|}
\hline Flows & Years & $\begin{array}{l}\text { Max } \\
\text { Obs }\end{array}$ & Used Obs & Comment \\
\hline $\begin{array}{l}274 \text { non London } \\
\text { long distance }\end{array}$ & 2006-2010 & 1370 & $\begin{array}{l}1367 \\
\quad(99.8 \%)\end{array}$ & 3 observations with missing revenue data \\
\hline $\begin{array}{l}138 \text { London } \\
\text { long distance }\end{array}$ & 1996-2001 & 828 & $\begin{array}{l}798 \\
\quad(96.4 \%)\end{array}$ & 30 observations with missing revenue data \\
\hline $\begin{array}{l}594 \text { non London } \\
\text { long distance }\end{array}$ & 1996-2001 & 3564 & $\begin{array}{l}3480 \\
\quad(97.6 \%)\end{array}$ & $\begin{array}{l}\text { Removed } 14 \text { flows to/from Stansted or Gatwick } \\
\text { Airports }\end{array}$ \\
\hline $\begin{array}{l}621 \text { London } \\
\text { long distance }\end{array}$ & 1995-2005 & 6831 & $\begin{array}{l}5154 \\
\quad(75.5 \%)\end{array}$ & $\begin{array}{l}\text { Removed to and from Birmingham Airport } \\
\text { Removed } 16 \text { observations no GJT data } \\
\text { Remove } 149 \text { flows with demand less than } 5 \text { return } \\
\text { trips per day }\end{array}$ \\
\hline $\begin{array}{l}2442 \text { non } \\
\text { London long } \\
\text { distance }^{\text {b }}\end{array}$ & 1995-2005 & 26,862 & $\begin{array}{l}25,465 \\
\quad(94.8 \%)\end{array}$ & $\begin{array}{l}\text { Removed } 127 \text { flows to or from Gatwick, } \\
\text { Manchester, Birmingham, Stansted and } \\
\text { Southampton Airports }\end{array}$ \\
\hline $\begin{array}{l}738 \text { non London } \\
\text { short distance }\end{array}$ & 1995-2005 & 8118 & $\begin{array}{l}8030 \\
\quad(98.9 \%)\end{array}$ & Removed 88 observations with no GJT data \\
\hline $\begin{array}{l}686 \text { South East } \\
\text { long distance }\end{array}$ & 1995-2005 & 7546 & $\begin{array}{l}6842 \\
(90.7 \%)\end{array}$ & $\begin{array}{l}\text { Remove } 64 \text { flows to/from Gatwick and Southampton } \\
\text { Airports }\end{array}$ \\
\hline
\end{tabular}

${ }^{\mathrm{a}, \mathrm{b}}$ There is an element of overlap with these respective data sets but the 1996-2001 datasets contain flows not included in the 1995-2005 datasets 
Table 3 Journey purposes by flow type for non-season tickets. Source: National Rail Passenger Survey

\begin{tabular}{llll}
\hline & Commuting $(\%)$ & Business $(\%)$ & Leisure (\%) \\
\hline London long & 14 & 36 & 50 \\
Non London long & 21 & 22 & 57 \\
Non London short & 31 & 13 & 56 \\
London and South East & 28 & 19 & 53 \\
\hline
\end{tabular}

\section{Model specification}

\section{The candidate model forms}

In conducting our tests of the central hypothesis of whether GC is justified, we estimate six different model forms for each of our data sets. These are:

- GJT-Fare: The standard GJT and fare model of the rail industry in Britain

- GC-Direct1: The GC formulation with a single directly estimated value of time.

- GC-Direct2: The GC formulation with a directly estimated value of time that is proportional to income. ${ }^{13}$

- GC-Meta: The GC formulation with the value of time derived from the meta-model of Eq. 10 below weighted by journey purpose.

- GC-Official: The GC formulation with the value of time based on official recommendations and weighted by journey purpose.

- SC: Splitting GJT into its separate components of in-vehicle-time, headway, interchange and, where possible, connection time

All models can be estimated by ordinary least squares regression except for GC-Direct1 and GC-Direct2 where non-linear least squares is required.

The mix of journey purposes used in calculating overall values of time in the GC-Meta and GC-Official models is set out in Table 3. Note that the results are not very sensitive to even quite large variations upon these journey purpose shares.

\section{GC and GJT weights}

The weights attached to headway and interchange in constructing GJT are set out in PDFH and we take these as given for the purposes of the analysis conducted here.

GC-Meta and GC-Official follow the conventional approach of adopting values of time (VoT) from prior evidence to construct GC. The former uses the values of time implied by the extensive meta-analysis of UK evidence reported in Abrantes and Wardman (2011) which is:

$$
V o T=G^{0.899} D^{0.161} e^{-5.80+0.75 E B+0.11 C o m m+0.23 I U+0.242 S E}
$$

VoT is in pence per minute in 2008 quarter four prices, D denotes distance in miles, $\mathrm{G}$ is GDP per capita with an index of 5927, EB and Comm are dummy variables denoting the

${ }_{13}$ We did experiment with freely estimating both the value of time and its income elasticity but this proved to be a 'step too far'!. 
purposes of employer's business and commuting, IU denotes whether the trip is interurban, which is deemed to be over 20 miles, and SE represents a journey made in the South East of England which is more affluent as well as having one of the densest rail networks in the world.

Another source of values of time is, quite naturally, official UK recommendations. We used the values recommended when we commenced this research, which were 44.76 pence per minute for business, 11.35 for commuting, and 10.07 for leisure trips, in 2010 prices and incomes. The income elasticity is unity for business travel but 0.8 for all other trips in line with the Department for Transport recommendations at the time. ${ }^{14}$

\section{Other data}

The key external drivers of non-season rail demand are economic activity and income, and the models reported here contain regional GVA per capita specified for the origin station. Of course, other variables impact on rail demand, such as car ownership levels, population, and the costs, journey times and service frequencies of other modes. We have not included these terms for a number of reasons. Firstly, obtaining reliable historic evidence on some of these terms, such as route specific car journey times and bus fares and service frequencies, is notoriously difficult. Secondly, some of the external factors tend to be highly correlated, such as income, car ownership, population and in some years car fuel costs. Thirdly, the cross-elasticity effects tend to be of second-order (ATOC 2013; TRL et al. 2004; TRRL 1980). ${ }^{15}$ Finally, some of these influences, especially those that vary little over time, will have been discerned by the fixed effects in our estimated models. Taken overall, we feel it is highly unlikely that the conclusions we draw would have been materially altered with the inclusion of a wide range of other factors even if it were possible to reliably do so.

\section{Model form}

The reported models take the following general form:

$$
V_{i j t}=\tau \prod_{k=1}^{n} X_{i j k t}^{\alpha_{k}} e^{\sum_{l=1}^{m} \beta_{l} X_{i j l t}} e^{\sum_{r=1}^{s} \gamma_{r} D_{i j r t}}
$$

$V_{i j t}$ is the demand for rail travel between stations $\mathrm{i}$ and $\mathrm{j}$ in time period $\mathrm{t}$. It is a function of $\mathrm{n}$ continuous variables $\left(X_{i j k t}\right)$, entered so that their coefficients $\left(\alpha_{k}\right)$ are interpreted as elasticities, and $\mathrm{m}$ continuous variables $\left(X_{i j l t}\right)$, entered so that their coefficients $\left(\beta_{l}\right)$ denote the proportionate change in demand after a unit change in the variable whereupon the elasticity is then proportional to the level of the variable $\left(\beta_{l} X_{i j l t}\right)$. In addition, there are $s$ discrete variables denoted by the dummy variables $\left(D_{i j r t}\right)$ and their coefficients $\left(\gamma_{r}\right)$ denote the proportionate effect on demand of a particularly category of a variable relative to an arbitrarily selected base category.

\footnotetext{
${ }^{14}$ The UK Department for Transport has recently revised its official valuations. Nonetheless, the officially recommended values of time over the periods of the data we have analysed are more appropriate since they would have been used in creating GC at the time.

15 Indeed, the required homogeneity of degree zero of a full demand system implies that all cross-elasticities for substitutes must be smaller than the own-elasticity, even more so if the income elasticity is positive.
} 
We explored both fixed-effects (FE) and the more parsimonious random-effects (RE) specifications. The FE specification is equivalent to dummy variables $\left(D_{i j r t}\right)$ for $\mathrm{p}-1$ of the $\mathrm{p}$ station-to-station movements without any variation by time period $\mathrm{t}$, effectively estimating route specific intercepts, and is potentially useful for controlling for unobserved heterogeneity over the cross-sections when that heterogeneity is constant over time. By contrast, a RE specification assumes that any differences between cross-sections are essentially random and that all cross-sections have been drawn from the same underlying population.

For each flow type, we computed two statistics to test whether a FE or RE specification of the GJT-Fare model was preferred. The first test is of an $F$ statistic that tests the null hypothesis that the fixed-effect parameters are all zero. Rejection of the null hypothesis suggests an FE specification may be appropriate. The second test is of a Hausman $m$ statistic that provides information about the appropriateness of the RE specification. The $m$ statistic is based on the idea that, under the null hypothesis of no correlation between the effects variables and the regressors, OLS and GLS are consistent, but OLS is inefficient. Hence, the test is based on the result that the covariance of an efficient estimator with its difference from an inefficient estimator is zero (SAS Institute 2011). Rejection of the null hypothesis suggests that an FE specification may be more appropriate.

In general, the greater the number of cross-sections (and the greater their within-crosssection homogeneity and between-cross-section heterogeneity), the more likely it is that FE will be supported and RE not supported. This is especially so as sample size approaches population size.

The results in Table 4 indicate that the FE specification performed better than the RE specification for all flow types. In respect of the former, the F test statistics indicated that the models need to recognise the panel structure of the data; the fixed-effects were in all cases found to be jointly significant. With respect to the latter, the random-effects specifications were rejected convincingly based on the Hausman test. This means that crosssectional differences between routes are picked up by route-specific constants. Only in the Non-London Long Distance 1995-2005 segment is the case for FE not totally overwhelming. In the latter case, it is the shorter-distance trips (under 100 miles) which exhibit

Table 4 Tests of fixed effects versus random effects models

\begin{tabular}{|c|c|c|c|c|c|c|}
\hline & \multicolumn{3}{|c|}{$\mathrm{F}$ test of $\mathrm{H}_{0}$ : all fixed-effects $=0$} & \multicolumn{3}{|c|}{$\begin{array}{l}\text { Hausman test of } \mathrm{H}_{0} \text { : no } \\
\text { correlation between } \\
\text { effects and error term } \\
\text { (random-effects model) }\end{array}$} \\
\hline & F value & $\begin{array}{l}d f \\
\text { (num/den) }\end{array}$ & $\operatorname{Pr}>F$ & $\begin{array}{l}\mathrm{m} \\
\text { value }\end{array}$ & Df & $\operatorname{Pr}>\mathrm{m}$ \\
\hline Non-London long distance 2006-2010 & 299.27 & $273 / 1090$ & $<0.0001$ & 80.90 & 3 & $<0.0001$ \\
\hline London long distance 1996-2001 & 260.71 & $133 / 637$ & $<0.0001$ & 36.14 & 3 & $<0.0001$ \\
\hline Non-London long distance 1996-2001 & 193.00 & $579 / 2897$ & $<0.0001$ & 85.51 & 3 & $<0.0001$ \\
\hline London long distance 1995-2005 & 728.99 & $496 / 4643$ & $<0.0001$ & 194.98 & 3 & $<0.0001$ \\
\hline Non-London long distance 1995-2005 & 391.19 & $2314 / 23,147$ & $<0.0001$ & 7.30 & 3 & 0.063 \\
\hline South East to and from London 1995-2005 & 770.97 & $621 / 6217$ & $<0.0001$ & 209.05 & 3 & $<0.0001$ \\
\hline Non-London short distance 1995-2005 & 203.46 & $729 / 7297$ & $<0.0001$ & 96.50 & 3 & $<0.0001$ \\
\hline
\end{tabular}


less unattributable route-specific variation. However, since we have not segmented by distance, we prefer its FE specification.

We subsequently proceed with the FE specification, although the (numerous) fixedeffect parameters are not reported. It turned out that the GJT, Fare and GVA elasticities from the FE and RE models were generally very similar as is reported in "Appendix".

\section{Empirical findings}

\section{Model outputs}

The model outputs for the seven sets of flows described in Table 2 are reported in Tables 5 , $6,7,8,9,10$ and 11, with long distance London flows first, followed by long distance Non London flows and then the South East flows and finally the short distance Non London flows. The estimated models are logarithmic transformations of Eq. 11 and the SAS package was used. These models are estimated by ordinary least squares, except GCDirect1 and GC-Direct2 where non-linear least squares is used to enable estimation of the VoT within GC.

Common elements of each table and each model are the GVA per capita elasticity estimate, the residual sum of squares (RSS), the adjusted $\mathrm{R}^{2}$ goodness of fit measure (ADJ $\mathrm{R}^{2}$ ) and, in the table heading, the number of observations. The GC, GJT, fare, headway, IVT and station-to-station time (TIME) coefficient estimates are all elasticities $\left(\mathrm{X}_{\mathrm{ijkt}}\right.$ in Eq. 11). INT denotes the number of interchanges and CONN is any connection time $\left(\mathrm{X}_{\mathrm{ijl}}\right.$ in Eq. 11) which are entered in absolute form since they can be zero. The $t$ ratio for each coefficient estimate is reported in brackets.

VoT-Est denotes an estimated value of time, in pence per minute. For the GC-Direct2 model, where the value of time is forced to increase in line with income, it denotes the estimated value of time for the first year before the subsequent income effect.

The row denoted VoT takes several forms. For the GJT-Fare model and the SC model it is the mean value of time across flows for the first and last years in the data set deduced using Eq. 5. For GC-Direct1 it is the constant directly estimated VoT. For the other cases, we report the mean value for the first and last year in the data set. GC-Direct2 and GCOfficial have common VoTs across flows and hence the standard errors, given in brackets, are zero.

The rows denoted $\eta_{\text {GJT }}$ and $\eta_{\text {FARE }}$ report the mean GJT and fare elasticities respectively implied by the four GC approaches for the first and last years in the respective data sets, along with their standard errors in brackets. For the SC model in the final column, $\eta_{\mathrm{GJT}}$ is the sum of $\alpha, \beta$ and $\psi \mathrm{I}$ of Eq. 9, where I is taken as its mean level in the data for the years in question. Where connection time is separately identified, then its contribution to $\eta_{\mathrm{GJT}}$ is its coefficient estimate multiplied by the mean amount of connection time.

For the models reported in Tables 6, 8 and 9, the Durbin-Watson statistic was in the range 1.6-2.0. This indicates autocorrelation is not an issue. In the other tables, which all cover the 1995-2005 data, the Durbin-Watson statistic was very much centred around 1. Nonetheless, the $t$ ratios are so large that allowing for autocorrelation, or indeed inspecting and correcting for heteroscedasticity, would not make a material difference to the confidence that could be placed in the parameter estimates.

In all models, the GJT, fare and GC elasticities are precisely estimated, almost always extremely so, and the GJT and fare elasticity estimates are on the whole very credible and 


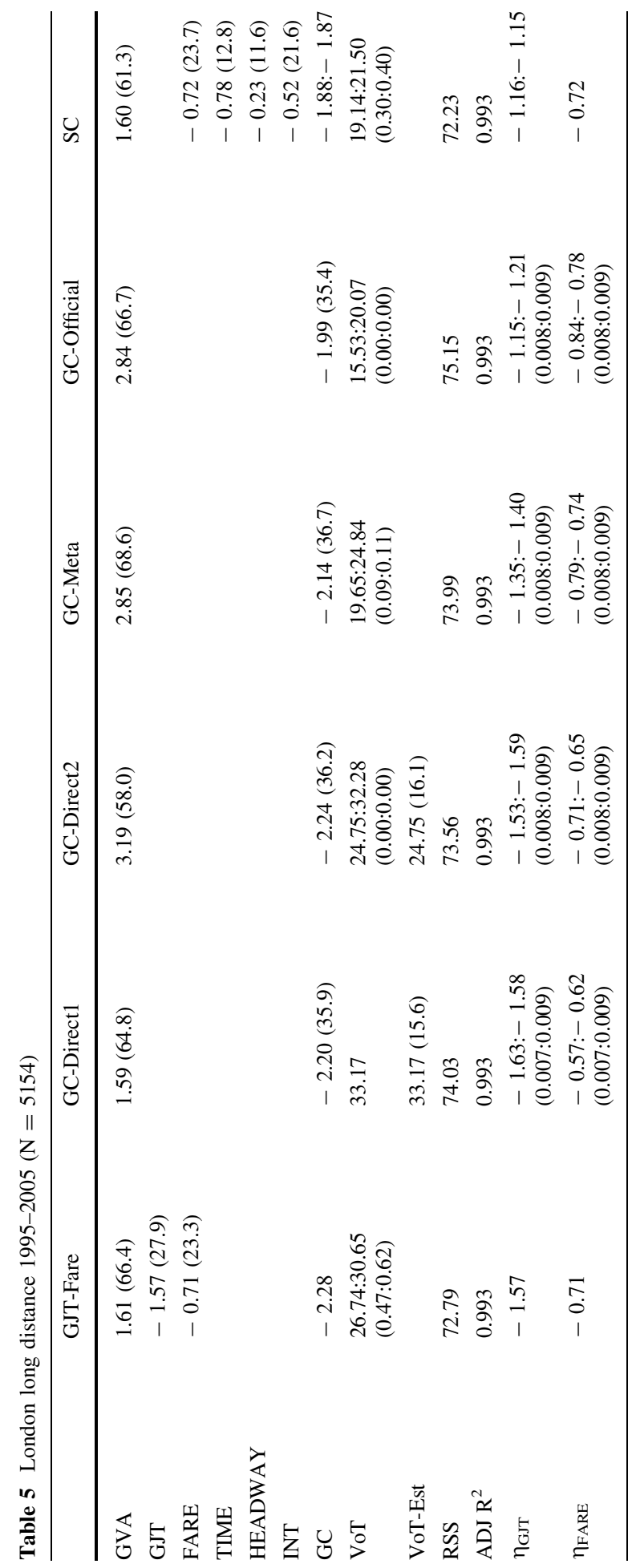




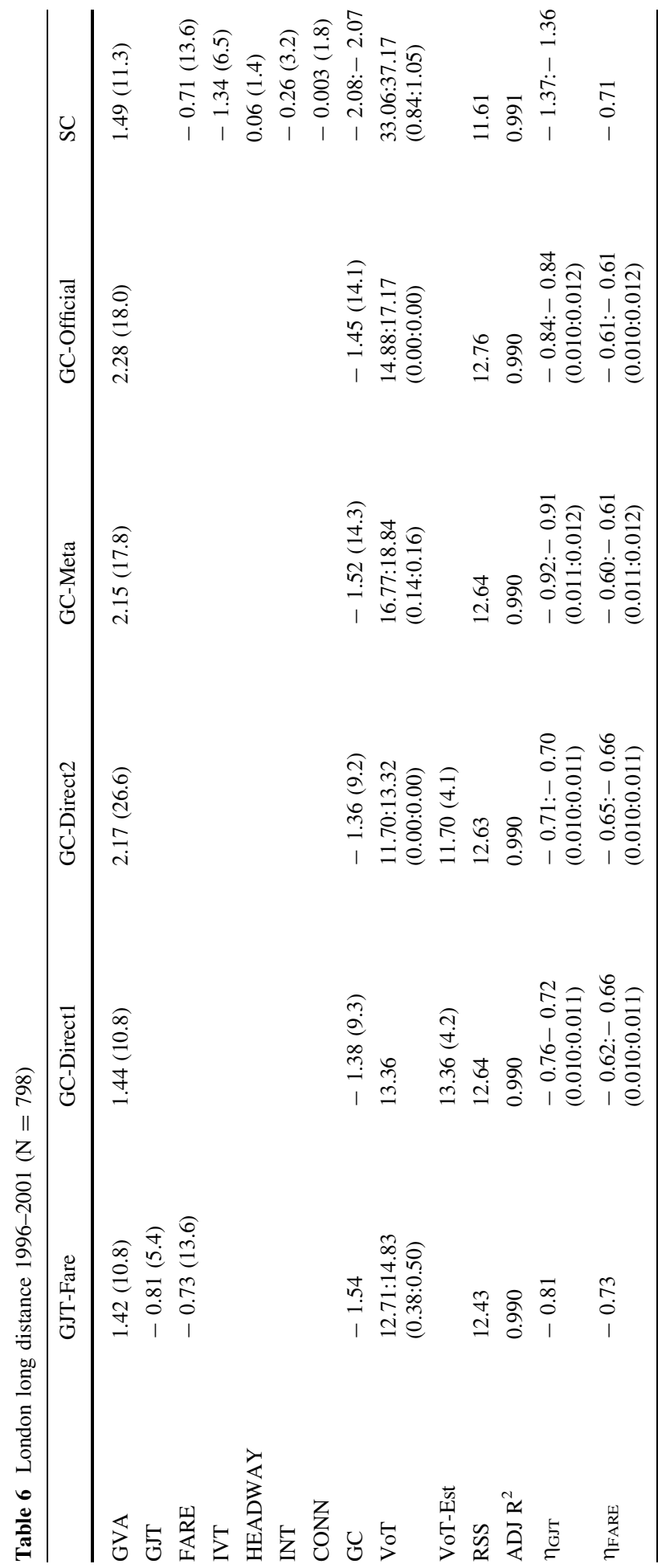




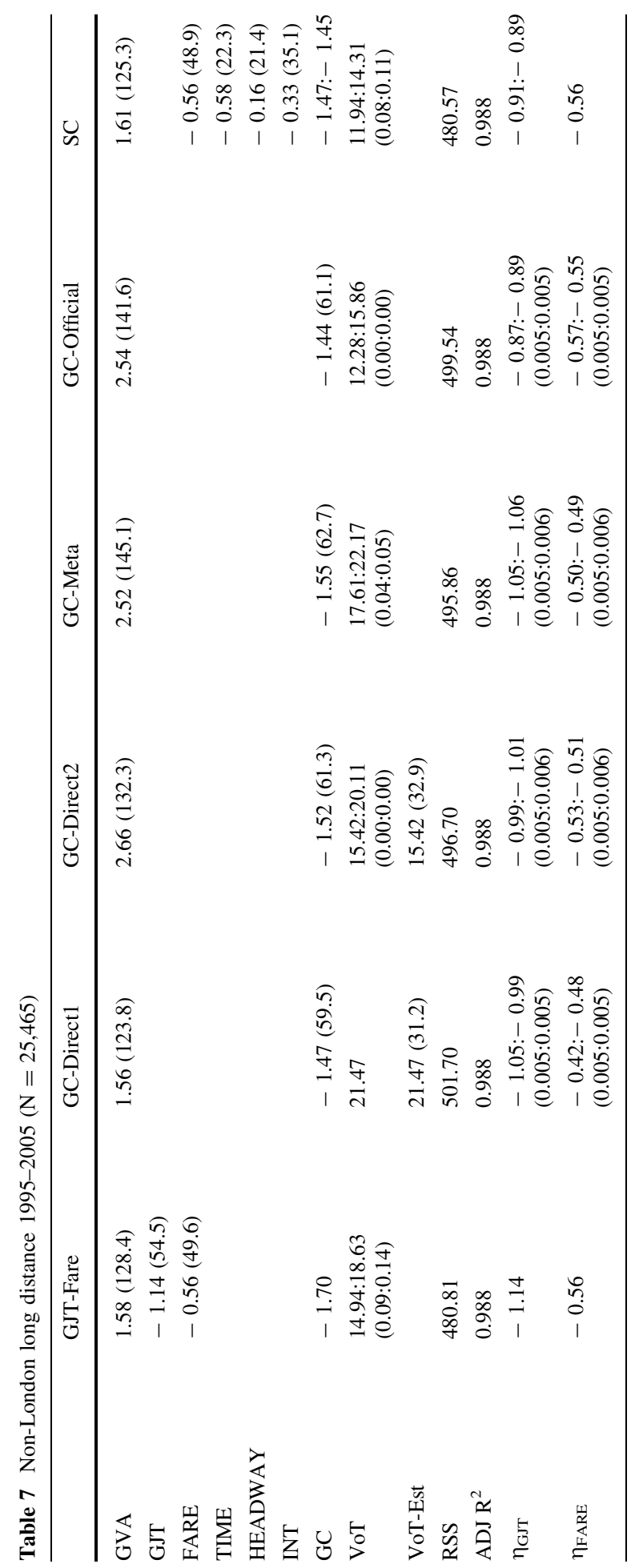


Table 8 Non-London long distance 1996-2001 ( $\mathrm{N}=3480)$

\begin{tabular}{|c|c|c|c|c|c|c|}
\hline & GJT-Fare & GC-Direct1 & GC-Direct2 & GC-Meta & GC-Official & $\mathrm{SC}$ \\
\hline GVA & $1.18(12.8)$ & $1.27(13.6)$ & $2.47(35.3)$ & $2.11(30.8)$ & $2.43(35.1)$ & $1.47(15.8)$ \\
\hline GJT & $\begin{array}{r}-1.22 \\
(23.1)\end{array}$ & & & & & \\
\hline FARE & $\begin{array}{r}-1.12 \\
(21.2)\end{array}$ & & & & & $-1.15(21.8)$ \\
\hline IVT & & & & & & $-0.54(6.6)$ \\
\hline HEAD & & & & & & $0.01(0.6)$ \\
\hline INT & & & & & & $-0.29(14.7)$ \\
\hline CONN & & & & & & $0.00(0.1)$ \\
\hline GC & -2.34 & $-2.19(33.1)$ & $-2.22(33.1)$ & $-2.03(31.0)$ & $-2.05(31.5)$ & $-1.97:-1.86$ \\
\hline VoT & $\begin{array}{l}5.96: 7.20 \\
(0.08: 0.12)\end{array}$ & 6.78 & $\begin{array}{l}6.06: 6.90 \\
(0.00: 0.00)\end{array}$ & $\begin{array}{l}15.08: 16.95 \\
(0.07: 0.08)\end{array}$ & $\begin{array}{l}11.76: 13.57 \\
(0.00: 0.00)\end{array}$ & $\begin{array}{l}5.22: 5.53 \\
(0.07: 0.09)\end{array}$ \\
\hline $\begin{array}{l}\text { VoT- } \\
\text { Est }\end{array}$ & & $6.78(13.0)$ & $6.06(13.2)$ & & & \\
\hline RSS & 94.59 & 95.91 & 95.88 & 99.40 & 98.70 & 93.68 \\
\hline $\begin{array}{r}\mathrm{ADJ} \\
\mathrm{R}^{2}\end{array}$ & 0.979 & 0.979 & 0.979 & 0.978 & 0.979 & 0.979 \\
\hline$\eta_{\mathrm{GJT}}$ & -1.22 & $\begin{array}{l}-1.24:-1.15 \\
(0.007: 0.008)\end{array}$ & $\begin{array}{l}-1.19:-1.17 \\
(0.008: 0.009)\end{array}$ & $\begin{array}{l}-1.50:-1.48 \\
(0.005: 0.006)\end{array}$ & $\begin{array}{l}-1.41:-1.40 \\
(0.006: 0.007)\end{array}$ & $\begin{array}{c}-0.82: \\
-0.71\end{array}$ \\
\hline$\eta_{\text {FARE }}$ & -1.12 & $\begin{array}{l}-0.95:-1.04 \\
(0.007: 0.008)\end{array}$ & $\begin{array}{l}-1.03:-1.05 \\
(0.008: 0.009)\end{array}$ & $\begin{array}{l}-0.53:-0.55 \\
(0.005: 0.006)\end{array}$ & $\begin{array}{l}-0.64:-0.65 \\
(0.006: 0.007)\end{array}$ & -1.15 \\
\hline
\end{tabular}

broadly in line with PDFH recommendations and major reviews and meta-analyses of UK evidence on fare elasticities (Wardman 2014) and GJT elasticities (Wardman 2012). ${ }^{16} \mathrm{We}$ conclude that the data sets provide a very firm basis for our tests.

The SC model is not central to the hypotheses here being tested but the results are of interest not only because its performance relative to other model forms indicates that it warrants further and more detailed attention but also because we here provide new evidence where little exists. The IVT/TIME elasticity is generally estimated very precisely and in all but one case, where it exceeds the estimated GJT elasticity, it is plausible. The importance of interchange comes across very clearly and the headway elasticity estimates are plausible and highly significant in four of the seven cases. The results for CONN are disappointing, but correlation with INT could be an explanatory factor. Nonetheless, the general credibility of the separate estimates for variables that underpin GJT gives us further confidence that our GJT data provides a robust basis for the tests we are undertaking.

The other key elasticity estimate relates to GVA per capita which is specified relative to the origin station. A noticeable feature of the result in Table 9 is that the GVA elasticity is negative. This is because over the period there was a sharp contraction in GVA yet for complex reasons beyond the scope of this investigation rail demand continued to increase. We do not feel though that this invalidates the investigation of our key hypotheses for this dataset.

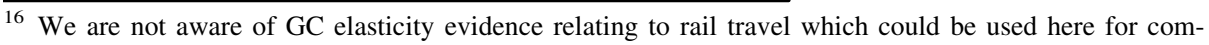
parison purposes.
} 


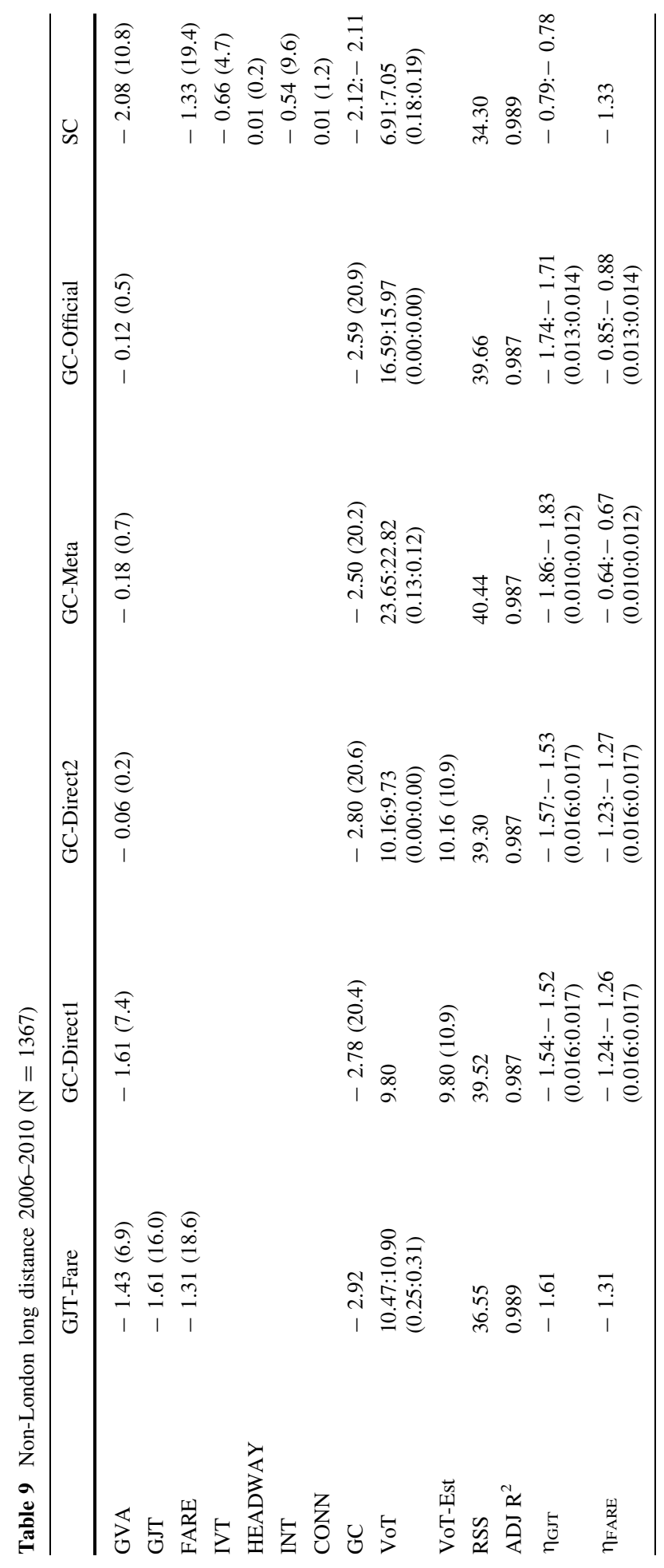




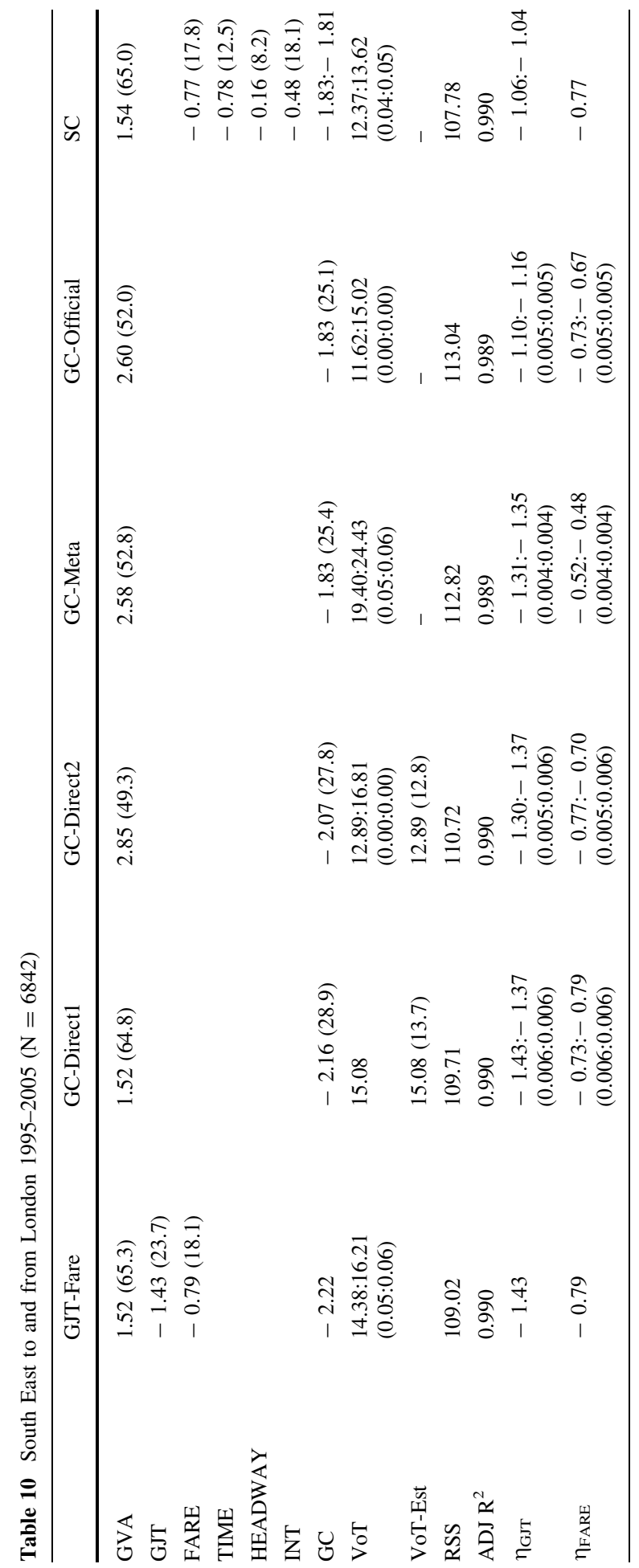




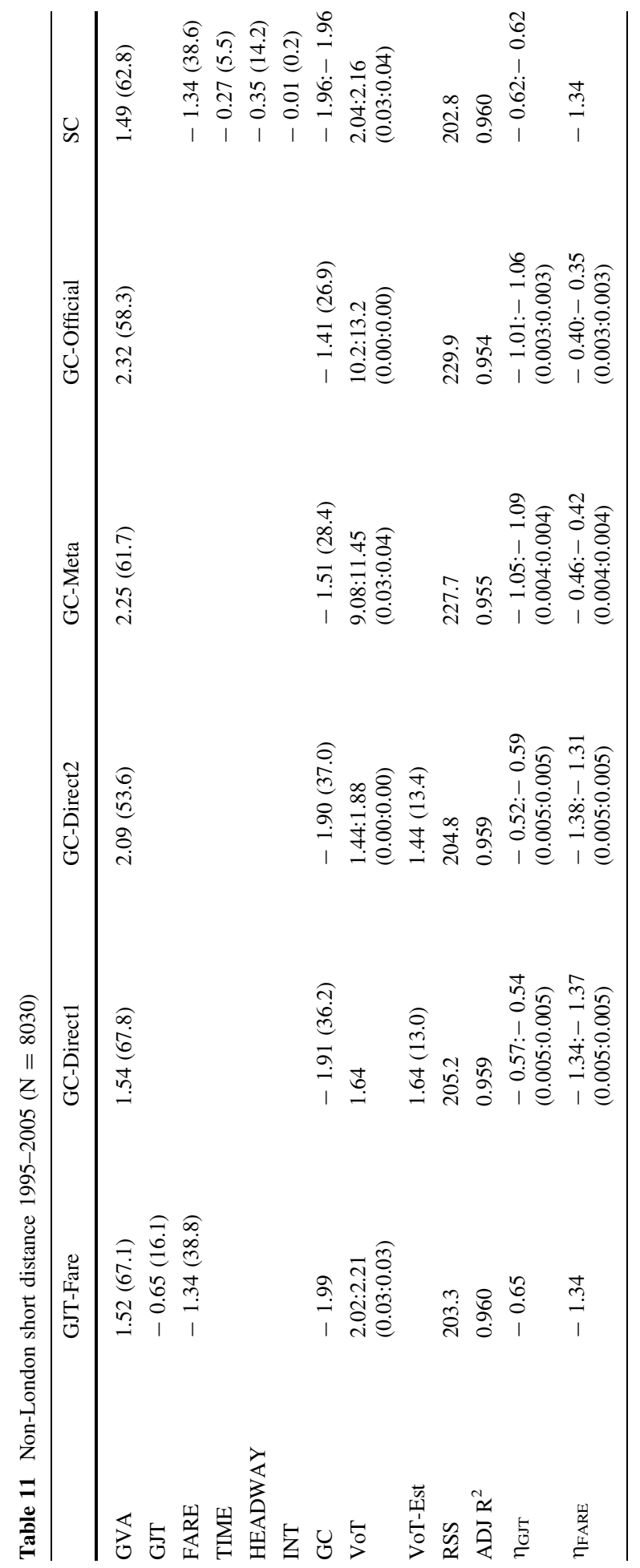


But more importantly, it can be seen that the GVA elasticity is very similar across the GJT-Fare, GC-Direct1 and SC models, which contain no other income term. For the GCDirect2, GC-Meta, and GC-Official models, which contain income within the value of time element of GC, the coefficient on GVA is more positive. In these cases the true GVA elasticity is the coefficient on GVA plus a fraction of the GC elasticity which, being negative, means the true GVA elasticity is less than the GVA coefficient. For example in Table 6, approximately $60 \%$ of the GC elasticity needs to be taken off the 'direct' GVA elasticity in order to generate the 'true' GVA elasticity. Once this adjustment is undertaken, the GVA elasticities for the cases where VoT depends on income are broadly comparable to those where VoT does not depend on income. Thus the central story as regards GVA is that all six model forms give similar results on any given data set.

The remaining parameter that we estimate is VoT. We are not aware of direct demand models outside this stream of work that have directly estimated VoT. The VoTs are estimated extremely precisely. These estimated values along with the prior official and meta-analysis values used are central to the hypotheses here being tested and are summarised and discussed in "Insights into values of time" section.

A key feature of this research investigation is the extent to which the GJT and fare elasticities implied by the GC models are consistent with the freely estimated elasticities. We provide summary statistics and discussion surrounding them in "Implied and directly estimated GJT and fare elasticities" section but note some patterns here. The models which directly estimate the VoT can be seen to provide average implied GJT and fare elasticities that are broadly in line with the directly estimated GJT and fare elasticities. This is not the case with the models using pre-specified values, where there is a tendency to place too much weight on the impact of GJT changes and too little on fare changes. This is hardly surprising given that the prior VoTs are generally larger than the freely estimated VoTs.

Our view is that we have here an impressive set of plausible, precise and in some regards original estimates, and that these provide a firm basis for the pioneering tests that we are here conducting. We now discuss these tests and investigations in more detail. These cover:

- Goodness of fit comparisons of different model forms

- Comparisons of directly estimated GJT and Fare elasticities with those implied by the GC approach and of directly estimated and implied GC elasticities

- Insights into values of time

- Explicit testing of the elasticity variation implied by the GC approach

\section{Relative goodness of fit}

Although not the single nor indeed most important criterion against which we assess the model outputs, it is informative to compare how the different models compare in terms of how well they explain the data.

For models with the same number of parameters, we can simply compare the adjusted $\mathrm{R}^{2}$ or RSS. This can be done for the GJT-Fare, GC-Direct1 and GC-Direct 2 models and also for GC-Meta and GC-Official models. However, the latter two have one less estimated parameter and hence we use an F test to compare the GC-Meta and GC-Official models as restricted cases of the GJT-Fare, GC-Direct1 and GC-Direct2 models and to compare the SC model with any other restricted model. The test $\mathrm{F}$ statistic is based on the residual sum of squares of the restricted $\left(\mathrm{RSS}_{\mathrm{R}}\right)$ and unrestricted $\left(\mathrm{RSS}_{\mathrm{U}}\right)$ models as: 
Table 12 Relative goodness of fit

\begin{tabular}{|c|c|c|c|c|c|c|}
\hline & 1 st & 2nd & $3 \mathrm{rd}$ & 4th & 5th & 6th \\
\hline London long distance 1995-2005 & $\mathrm{SC}$ & $\begin{array}{l}\text { GJT- } \\
\text { Fare }\end{array}$ & $\begin{array}{l}\text { GC- } \\
\text { Direct2 }\end{array}$ & GC-Meta & $\begin{array}{l}\text { GC- } \\
\text { Direct1 }\end{array}$ & $\begin{array}{l}\text { GC- } \\
\text { Official }\end{array}$ \\
\hline London long distance 1996-2001 & $\mathrm{SC}$ & $\begin{array}{l}\text { GJT- } \\
\text { Fare }\end{array}$ & GC-Meta & $\begin{array}{l}\text { GC- } \\
\text { Direct2 }\end{array}$ & $\begin{array}{l}\text { GC- } \\
\text { Direct1 }\end{array}$ & $\begin{array}{l}\text { GC- } \\
\text { Official }\end{array}$ \\
\hline Non-London long distance 1995-2005 & $\mathrm{SC}$ & $\begin{array}{l}\text { GJT- } \\
\text { Fare }\end{array}$ & GC-Meta & $\begin{array}{l}\text { GC- } \\
\text { Direct2 }\end{array}$ & $\begin{array}{l}\text { GC- } \\
\text { Official }\end{array}$ & $\begin{array}{l}\text { GC- } \\
\text { Direct1 }\end{array}$ \\
\hline Non-London long distance 1996-2001 & $\mathrm{SC}$ & $\begin{array}{l}\text { GJT- } \\
\text { Fare }\end{array}$ & $\begin{array}{l}\text { GC- } \\
\text { Direct2 }\end{array}$ & $\begin{array}{l}\text { GC- } \\
\text { Direct1 }\end{array}$ & $\begin{array}{l}\text { GC- } \\
\text { Official }\end{array}$ & GC-Meta \\
\hline Non-London long distance 2006-2010 & $\mathrm{SC}$ & $\begin{array}{l}\text { GJT- } \\
\text { Fare }\end{array}$ & $\begin{array}{l}\text { GC- } \\
\text { Direct2 }\end{array}$ & $\begin{array}{l}\text { GC- } \\
\text { Direct1 }\end{array}$ & $\begin{array}{l}\text { GC- } \\
\text { Official }\end{array}$ & GC-Meta \\
\hline $\begin{array}{l}\text { South East to and from London } \\
1995-2005\end{array}$ & $\mathrm{SC}$ & $\begin{array}{l}\text { GJT- } \\
\text { Fare }\end{array}$ & $\begin{array}{l}\text { GC- } \\
\text { Direct1 }\end{array}$ & $\begin{array}{l}\text { GC- } \\
\text { Direct2 }\end{array}$ & GC-Meta & $\begin{array}{l}\text { GC- } \\
\text { Official }\end{array}$ \\
\hline Non-London short distance 1995-2005 & $\mathrm{SC}$ & $\begin{array}{l}\text { GJT- } \\
\text { Fare }\end{array}$ & $\begin{array}{l}\text { GC- } \\
\text { Direct2 }\end{array}$ & $\begin{array}{l}\text { GC- } \\
\text { Direct1 }\end{array}$ & GC-Meta & $\begin{array}{l}\text { GC- } \\
\text { Official }\end{array}$ \\
\hline
\end{tabular}

$$
F=\frac{\left(R S S_{R}-R S S_{U}\right) / r}{R S S_{U} /(n-k)}
$$

with degrees of freedom $\mathrm{r}$, denoting the number of restrictions imposed, and $\mathrm{n}-\mathrm{k}$, where $\mathrm{n}$ is the number of observations and $\mathrm{k}$ is the number of estimated parameters.

Table 12 reports the relative explanatory performance across all six models for each of the seven datasets. Noticeably, the SC model provides the best fit in all cases. This is an interesting finding although one that impacts more on future research priorities and needs than on the tests we are here conducting.

Of more significance here is that the GJT-Fare specification always provides a better explanation of the data than the GC models. This is our first evidence that the GJT-Fare model is preferable to various forms of the standard GC expression as typically formulated.

Another notable pattern in Table 12 is that GC-Direct2, which freely estimates a VoT that increases in line with income, is in all but one case superior to GC-Direct1 where the freely estimated VoT is constant. This is reassuring given that the income effect is to be expected but is by no means guaranteed in such free estimation.

We also take confidence in the finding that the GC models with directly estimated VoTs, which the railway industry is generally in a position to undertake, generally perform better than GC models based on 'best evidence' and official values.

It is noticeable, but nonetheless unsurprising, that the GC models based on official values, which primarily serve purposes of economic appraisal, tend to be the worst performing. This is though, in our understanding, the conventional way in which GC would be constructed.

This evidence points to the GC approach being inferior to other formulations, and that if the GC approach is to be used it is preferable to base it on directly estimated VoT with best evidence VoT better than 'official' values. 
Table 13 Summary of implied and directly estimated GC, GJT and fare elasticities

\begin{tabular}{|c|c|c|c|c|c|c|}
\hline & GJT-Fare & GC-Direct1 & GC-Direct2 & GC-Meta & GC-Official & $\mathrm{SC}$ \\
\hline \multicolumn{7}{|c|}{ Average elasticities } \\
\hline GC & $-2.13(0.17)$ & $-2.01(0.18)$ & $-2.02(0.18)$ & $-1.87(0.14)$ & $-1.83(0.18)$ & $-1.89(0.08)$ \\
\hline GJT & $-1.20(0.14)$ & $-1.15(0.15)$ & $-1.13(0.15)$ & $-1.30(0.12)$ & $-1.17(0.12)$ & $-0.95(0.10)$ \\
\hline Fare & $-0.94(0.12)$ & $-0.86(0.13)$ & $-0.89(0.12)$ & $-0.57(0.04)$ & $-0.65(0.06)$ & $-0.94(0.12)$ \\
\hline \multicolumn{7}{|c|}{ Proportionate absolute deviation from GJT-fare model } \\
\hline GC & - & $0.06(0.015)$ & $0.06(0.013)$ & $0.12(0.030)$ & $0.15(0.028)$ & $0.19(0.041)$ \\
\hline GJT & - & 0.07 (0.019) & $0.08(0.021)$ & $0.21(0.076)$ & $0.22(0.069)$ & $0.33(0.079)$ \\
\hline Fare & - & $0.09(0.026)$ & $0.06(0.012)$ & $0.35(0.087)$ & $0.27(0.092)$ & $0.02(0.004)$ \\
\hline
\end{tabular}

Where elasticities vary, we take the average of the first and last year in the dataset

\section{Implied and directly estimated GJT and fare elasticities}

Table 13 summarises the previous evidence regarding implied and directly estimated elasticities. The first three rows provide the average directly estimated and implied GC, GJT and Fare elasticities for each model across the seven data sets along with their standard errors.

The GC elasticities on average do not vary greatly, and are not significantly different. This is encouraging since we can then explore how similar GC elasticities are decomposed into GJT and Fare elasticities.

Turning to the GJT and fare elasticities, on average the GC-Direct1 and GC-Direct2 models provide implied GJT and fare elasticities very similar to the directly estimated ones. GC-Meta tends to provide GJT elasticities a little larger than those directly estimated but somewhat lower fare elasticities with the GC-Official model on average performing well on GJT but poorly on fare. What is noticeable is that the official and review VoTs imply GJT elasticities around twice the fare elasticities, somewhat out of line with all other models. The SC model provides GJT elasticities farthest removed from those directly estimated but, as would be expected, its fare elasticities are very much in line with the GJT-Fare model.

Of course, average values of two parameters can be very similar even when the individual values are often somewhat different. We therefore report in the final three rows the means and associated standard errors of the proportionate absolute deviation of the direct and implied elasticities from those of the GJT-Fare model.

Whilst the proportionate deviations in the GC elasticities are significant in all cases, they are nonetheless small. This similarity of elasticities is though not the case with regard to GJT and fare. We can see that when the VoT is directly estimated the implied GJT and fare elasticities are on average less than $10 \%$ different to the directly estimated values. Contrast this with the cases where the VoT is based on prior evidence. Here the implied GJT elasticities of the GC-Meta and GC-Official models are on average just over $20 \%$ different to the directly estimated ones with corresponding figures of 35 and $27 \%$ for the fare elasticity. The SC model performs by far the poorest on implied relative to directly estimated GJT elasticities. We attribute this to the greater challenges of obtaining precise estimates when there are more service quality variables to be covered, including the increased possibilities of multicollinearity and of lack of variation in some of the more detailed attributes. 
Table 14 Summary of implied, directly estimated and prior values of time

\begin{tabular}{|c|c|c|c|c|c|c|}
\hline & GJT-Fare & GC-Direct1 & GC-Direct2 & GC-Meta & GC-Official & $\mathrm{SC}$ \\
\hline \multicolumn{7}{|c|}{ Average valuations } \\
\hline VOT & $13.38(3.20)$ & $14.47(3.92)$ & $13.10(3.26)$ & $18.77(1.72)$ & $14.55(0.83)$ & $13.71(4.23)$ \\
\hline \multicolumn{7}{|c|}{ Proportionate absolute deviation from GJT-Direct2 } \\
\hline & $0.08(0.035)$ & $0.07(0.030)$ & - & $1.32(0.675)$ & $1.23(0.810)$ & $0.45(0.226)$ \\
\hline
\end{tabular}

Where the VoT varies, we use the mean across the first and last year in the data set. VoT is pence per minute

At the level of central estimates, it seems that the GC approach can approximate the GJT-Fare model well when the VoT is directly estimated but there are concerns when predetermined VoTs are used to construct GC.

\section{Insights into values of time}

Table 14 summarises the implied, directly estimated and prior VoTs for each model type in terms of their mean and associated standard errors. We are unaware of VoTs being directly estimated in this way from direct demand models.

On average, there is little to choose between the mean VoTs except for the larger value of the GC-Meta model. However, when we inspect the proportionate absolute deviation relative to GC-Direct2, given that it directly estimates a VoT that is allowed to increase with income, we see a very close correspondence with the freely estimated but constant VoT of GC-Direct1 and with the implied values of the GJT-Fare model. The VoTs based on prior evidence are very different on average.

This evidence is indicating that the averages of the directly estimated VoTs are similar to each other and to that implied by the GJT-Fare model but are distinctly different to the official and meta-analysis evidence. The VoTs implied by the SC model differ but are on average closer to the former than the latter. In several cases, the standard approach of using 'best evidence' would involve VoTs somewhat different to those which best explain rail demand and implied by the balance between time and price elasticities.

\section{Testing the implied elasticity variation}

So far, we have compared at an average level actual and implied elasticities and values of time along with explanatory performance. However, a more rigorous test of the GC approach, whichever of our types, is to examine the spread of implied elasticities rather than just the means. Are the variations in the GJT and Fare elasticities implied by the GC approach empirically justified?

Equations 3 and 4 denote the dependence of the implied GJT and fare elasticities of the GC approach on the proportion that each forms of GC. We therefore created dummy variables denoting five different categories of expected elasticity according to the proportion that GJT and Fare form of GC. In order to avoid endogeneity problems, the five 
categories on each flow are defined for the first year in the time-series ${ }^{17}$ and are created using the constant VoT of the GC-Direct1 model.

We then specify an extended GJT-Fare model that allows the GJT and Fare elasticities to vary with the proportion that each forms of GC. Ignoring terms other than GJT and fare, this model takes the form:

$$
\begin{aligned}
\ln V_{i j t}= & \delta_{1} G J T_{i j t}+\delta_{2} d_{2} G J T_{i j t}+\delta_{3} d_{3} G J T_{i j t}+\delta_{4} d_{4} G J T_{i j t}+\delta_{5} d_{5} G J T_{i j t}+\gamma_{1} F_{i j t}+\gamma_{2} d_{2} F_{i j t} \\
& +\gamma_{3} d_{3} F_{i j t}+\gamma_{4} d_{4} F_{i j t}+\gamma_{5} d_{5} F_{i j t}
\end{aligned}
$$

The $d_{2}, d_{3}, d_{4}$ and $d_{5}$ are dummy variables denoting sensible categorisations of expected elasticity variation. We use five categories to provide a more rigorous test, given that the previously reported models have very precisely estimated elasticities to GJT and fare and hence can support so many categories. ${ }^{18}$

Interpreting the model parameters with regard to GJT, the base elasticity is $\delta_{1}$. For the second expected elasticity category the GJT elasticity is $\delta_{1}+\delta_{2}$ and for the fifth it is $\delta_{1}+\delta_{5}$. Given that we specify the dummy variables to denote increasing proportions that GJT forms of GC, we would expect that $\delta_{5}<\delta_{4}<\delta_{3}<\delta_{2}<0$. For fare we would expect that $\gamma_{5}>\gamma_{4}>\gamma_{3}>\gamma_{2}>0$.

Table 15 reports the segmented models for each flow type, covering quite large variations in expected elasticity variation but bearing in mind the split of observations across each category. Exp $\eta_{\mathrm{GJT}}$ and Exp $\eta_{\mathrm{F}}$ denote the expected elasticity categories for GJT and fare respectively with Est $\eta_{\text {GJT }}$ and Est $\eta_{F}$ reporting the estimates of Eq. 13. The first column of results provides the base GJT or fare elasticity and their t statistics. These are for categories that are the lowest (highest) proportions that GJT (fare) forms of GC. The properties of the GC approach would require that as we move to the right in Table 15 the incremental effects should imply a GJT (fare) elasticity that becomes more (less) negative.

Encouragingly, all the base GJT and Fare elasticities are statistically significant, and almost all are estimated with a high level of precision. However, around $40 \%$ of the incremental effects were not significant at the usual 5\% level. Moreover, it is only in the case of the GJT elasticity for South East to and from London flows that there is a convincing case in support of the GC implied elasticity variation, although a few more instances could be argued to possibly support the GC approach but then relying on the argument that all else is not equal across the various categories. We should also point out that the pattern of results was not greatly different when the segmentations of the GJT elasticity and the fare elasticity were conducted separately.

We conclude that robust models, with large sample sizes and plausible and very precise coefficient estimates in their standard form, are not able to support the variation in GJT and fare elasticities that would be implied by the GC approach.

\footnotetext{
17 The numbers in each category do not vary much depending upon whether the categories are defined for the first year or separately for each year. And the conclusions are not altered when the latter specification was used.

${ }^{18}$ We experimented with four and three categories, but the findings would not alter our conclusions.
} 
Table 15 Segmented elasticities: comparison of expected and estimated elasticities

\section{London long distance 1995-2005}

$\begin{array}{lll}\text { Exp } \eta_{\mathrm{GJT}} & \leq 0.60 \eta_{\mathrm{GC}} & 0.61 \eta_{\mathrm{GC}}-0.65 \eta_{\mathrm{GC}} \\ \text { Est } \eta_{\mathrm{GJT}} & -1.63(22.6) & +0.37(2.7) \\ \text { Exp } \eta_{\mathrm{F}} & >0.40 \eta_{\mathrm{GC}} & 0.35 \eta_{\mathrm{GC}}-0.39 \eta_{\mathrm{GC}} \\ \text { Est } \eta_{\mathrm{F}} & -0.72(12.7) & -0.02(0.2) \\ \text { Obs } & 838 & 590\end{array}$

London long distance 1996-2001

$\begin{array}{lll}\text { Exp } \eta_{\mathrm{GJT}} & \leq 0.40 \eta_{\mathrm{GC}} & 0.41 \eta_{\mathrm{GC}}-0.45 \eta_{\mathrm{GC}} \\ \text { Est } \eta_{\mathrm{GJT}} & -0.40(2.1) & -0.38(3.4) \\ \text { Exp } \eta_{\mathrm{F}} & >0.60 \eta_{\mathrm{GC}} & 0.55 \eta_{\mathrm{GC}}-0.59 \eta_{\mathrm{GC}} \\ \text { Est } \eta_{\mathrm{F}} & -1.35(10.7) & +0.59(3.3) \\ \text { Obs } & 63 & 127\end{array}$

Non-London long distance 1995-2005

$\begin{array}{lll}\text { Exp } \eta_{\mathrm{GJT}} & \leq 0.60 \eta_{\mathrm{GC}} & 0.61 \eta_{\mathrm{GC}}-0.65 \eta_{\mathrm{GC}} \\ \text { Est } \eta_{\mathrm{GJT}} & -1.07(17.6) & -0.01(0.1) \\ \text { Exp } \eta_{\mathrm{F}} & >0.40 \eta_{\mathrm{GC}} & 0.35 \eta_{\mathrm{GC}}-0.39 \eta_{\mathrm{GC}} \\ \text { Est } \eta_{\mathrm{F}} & -0.32(12.6) & -0.10(3.1) \\ \text { Obs } & 2695 & 3894\end{array}$

Non-London long distance 1996-2001

$\begin{array}{lll}\text { Exp } \eta_{\mathrm{GJT}} & \leq 0.45 \eta_{\mathrm{GC}} & 0.46 \eta_{\mathrm{GC}}-0.50 \eta_{\mathrm{GC}} \\ \text { Est } \eta_{\mathrm{GJT}} & -1.32(12.5) & +0.65(4.6) \\ \text { Exp } \eta_{\mathrm{F}} & >0.55 \eta_{\mathrm{GC}} & 0.50 \eta_{\mathrm{GC}}-0.54 \eta_{\mathrm{GC}} \\ \text { Est } \eta_{\mathrm{F}} & -1.16(10.3) & +0.35(2.3) \\ \text { Obs } & 493 & 665\end{array}$

Non-London long distance 2006-2010

$\begin{array}{lll}\text { Exp } \eta_{\mathrm{GJT}} & \leq 0.40 \eta_{\mathrm{GC}} & 0.41 \eta_{\mathrm{GC}}-0.45 \eta_{\mathrm{GC}} \\ \text { Est } \eta_{\mathrm{GJT}} & -2.23(6.3) & +0.70(1.5) \\ \text { Exp } \eta_{\mathrm{F}} & >0.60 \eta_{\mathrm{GC}} & 0.55 \eta_{\mathrm{GC}}-0.59 \eta_{\mathrm{GC}} \\ \text { Est } \eta_{\mathrm{F}} & -2.51(7.5) & +1.49(3.2) \\ \text { Obs } & 65 & 135\end{array}$

South East to and from London 1995-2005

$\begin{array}{lll}\text { Exp } \eta_{\mathrm{GJT}} & \leq 0.60 \eta_{\mathrm{GC}} & 0.61 \eta_{\mathrm{GC}}-0.65 \eta_{\mathrm{GC}} \\ \text { Est } \eta_{\mathrm{GJT}} & -1.00(5.0) & -0.40(1.7) \\ \text { Exp } \eta_{\mathrm{F}} & >0.40 \eta_{\mathrm{GC}} & 0.35 \eta_{\mathrm{GC}}-0.39 \eta_{\mathrm{GC}} \\ \text { Est } \eta_{\mathrm{F}} & -0.84(7.5) & +0.25(2.0) \\ \text { Obs } & 1045 & 1969\end{array}$

Non-London Short Distance 1995-2005

$\begin{array}{lll}\text { Exp } \eta_{\mathrm{GJT}} & \leq 0.20 \eta_{\mathrm{GC}} & 0.21 \eta_{\mathrm{GC}}-0.25 \eta_{\mathrm{GC}} \\ \text { Est } \eta_{\mathrm{GJT}} & -0.38(4.3) & -0.42(3.7) \\ \text { Exp } \eta_{\mathrm{F}} & >0.80 \eta_{\mathrm{GC}} & 0.75 \eta_{\mathrm{GC}}-0.79 \eta_{\mathrm{GC}} \\ \text { Est } \eta_{\mathrm{F}} & -0.82(9.2) & -0.45(4.0) \\ \text { Obs } & 1045 & 2002\end{array}$

$0.66 \eta_{\mathrm{GC}}-0.70 \eta_{\mathrm{GC}}$
$-0.07(1.3)$
$0.30 \eta_{\mathrm{GC}}-0.34 \eta_{\mathrm{GC}}$
$+0.09(1.1)$
1329

$0.46 \eta_{\mathrm{GC}}-0.50 \eta_{\mathrm{GC}}$ $-0.41(3.7)$

$0.54 \eta_{\mathrm{GC}}-0.50 \eta_{\mathrm{GC}}$ $+0.66(3.4)$

156

$0.66 \eta_{\mathrm{GC}}-0.70 \eta_{\mathrm{GC}}$ $+0.03(0.4)$

$0.30 \eta_{\mathrm{GC}}-0.34 \eta_{\mathrm{GC}}$ $-0.23(7.1)$

7337

$0.51 \eta_{\mathrm{GC}}-0.60 \eta_{\mathrm{GC}}$ +0.07 (0.6)

$0.40 \eta_{\mathrm{GC}}-0.49 \eta_{\mathrm{GC}}$

$+0.04(0.3)$

1542

$0.46 \eta_{\mathrm{GC}}-0.55 \eta_{\mathrm{GC}}$ +0.47 (1.2)

$0.45 \eta_{\mathrm{GC}}-0.54 \eta_{\mathrm{GC}}$

$+1.12(3.1)$

405

$0.66 \eta_{\mathrm{GC}}-0.70 \eta_{\mathrm{GC}}$ $-0.62(2.7)$

$0.30 \eta_{\mathrm{GC}}-0.34 \eta_{\mathrm{GC}}$ $+0.04(0.3)$

1958

$0.26 \eta_{\mathrm{GC}}-0.30 \eta_{\mathrm{GC}}$
$-0.18(1.5)$
$0.70 \eta_{\mathrm{GC}}-0.74 \eta_{\mathrm{GC}}$
$-1.06(9.4)$
2398

$0.71 \eta_{\mathrm{GC}}-0.75 \eta_{\mathrm{GC}}>0.75 \eta_{\mathrm{GC}}$ $-0.11(2.4)+0.09(1.9)$

$0.25 \eta_{\mathrm{GC}}-0.29 \eta_{\mathrm{GC}} \leq 0.25 \eta_{\mathrm{GC}}$ $+0.13(1.8) \quad-0.25(3.3)$ 1395

1002

$0.51 \eta_{\mathrm{GC}}-0.60 \eta_{\mathrm{GC}}>0.60 \eta_{\mathrm{GC}}$ $-0.45(4.1) \quad-0.31(1.0)$

$0.40 \eta_{\mathrm{GC}}-0.49 \eta_{\mathrm{GC}} \leq 0.40 \eta_{\mathrm{GC}}$ $+0.63(3.3) \quad-0.25(1.1)$

$236 \quad 216$

$0.71 \eta_{\mathrm{GC}}-0.75 \eta_{\mathrm{GC}}>0.75 \eta_{\mathrm{GC}}$ $-0.22(3.1)+0.06(0.7)$

$0.25 \eta_{\mathrm{GC}}-0.29 \eta_{\mathrm{GC}} \leq 0.25 \eta_{\mathrm{GC}}$ $-0.28(8.2) \quad-0.78(18.5)$ $6732 \quad 4807$

$0.60 \eta_{\mathrm{GC}}-0.65 \eta_{\mathrm{GC}}>0.65 \eta_{\mathrm{GC}}$ $-0.17(1.2) \quad-0.08(0.5)$

$0.35 \eta_{\mathrm{GC}}-0.40 \eta_{\mathrm{GC}} \leq 0.35 \eta_{\mathrm{GC}}$

$-0.04(0.2) \quad-0.74(2.8)$

$510 \quad 270$

$0.56 \eta_{\mathrm{GC}}-0.65 \eta_{\mathrm{GC}}>0.65 \eta_{\mathrm{GC}}$ $+0.73(1.8)+0.47(0.9)$

$0.35 \eta_{\mathrm{GC}}-0.44 \eta_{\mathrm{GC}} \leq 0.35 \eta_{\mathrm{GC}}$

$+1.21(3.4) \quad+1.50(3.9)$

$562 \quad 200$

$0.71 \eta_{\mathrm{GC}}-0.75 \eta_{\mathrm{GC}}>0.75 \eta_{\mathrm{GC}}$

$-0.15(0.7) \quad-0.86(3.3)$

$0.25 \eta_{\mathrm{GC}}-0.29 \eta_{\mathrm{GC}} \leq 0.25 \eta_{\mathrm{GC}}$

$-0.27(2.0) \quad+0.22(1.5)$

$1254 \quad 616$

$\begin{array}{ll}0.31 \eta_{\mathrm{GC}}-0.35 \eta_{\mathrm{GC}} & >0.35 \eta_{\mathrm{GC}} \\ -0.02(0.2) & -1.03(7.1) \\ 0.65 \eta_{\mathrm{GC}}-0.69 \eta_{\mathrm{GC}} & \leq 0.65 \eta_{\mathrm{GC}} \\ -0.28(2.4) & -0.75(6.1) \\ 1617 & 968\end{array}$




\section{Conclusions}

The GC formulation has been used in transport models for many years to represent the overall attractiveness of different alternatives and can be regarded as an industry standard'. Given its significant place in transport planning, modelling and forecasting, an observer might reasonably expect that its quite specific implied elasticity properties would have been subject to empirical testing, and indeed this point was made many years ago by Grey (1978a, b). That same informed observer might also ponder the stark contrast between the large variation in time and fare elasticities implied by the GC approach and the common failure of demand models to find statistical support for alternatives to the conventional constant elasticity formulation. Indeed, examination of the elasticity and value of time review literature raises serious questions surrounding the implied elasticity properties of GC models.

We contend that there has been little empirical questioning of the implied elasticity properties of the GC formulation, and also of the VoTs that underpin it, and moreover that the limitations of the GC approach have been forgotten, overlooked or not appreciated, and it is used because 'it has always been used'.

The research reported here is original and significant in conducting detailed tests of whether the GC approach is justified, directly estimating the VoT that should be used in constructing GC and making a significant contribution to the evidence base regarding a number of rail demand elasticities.

The opportunity to test the properties and parameters of the GC approach is afforded by the unique availability of large amounts of rail ticket sales data in Great Britain alongside the necessary variations in service quality attributes over time that complement more customary price variations. Such data sets and the required variations do not exist for other modes.

We have examined six model forms across seven different data sets. Four models are of the GC formulation, of which two represent conventional practice, with GC constructed using official values of time and best evidence as represented by the findings of metaanalysis, and two which can be regarded to be original in directly estimating the VoT within the GC function that best explains demand responses. The two alternatives to these GC formulations are a model based on GJT and fare (GJT-Fare), which represents the wellestablished analysis and forecasting approach used by railways in Great Britain, and an approach more akin to disaggregate model, where GJT is split into its separate components (SC) covering journey time, service headway, interchange and connection time.

The elasticities across the various models we report are generally plausible and estimated with a very high degree of precision whilst the directly estimated VoTs are almost always extremely precise. We therefore have a very firm basis for empirical testing of the GC approach.

In terms of our hypotheses set out in "The opportunity and aims" section, we have found that: 
- The industry standard GJT-Fare model always provided a better fit than our four candidate GC approaches. Amongst the GC models, those that directly estimate the VoT almost always provided a better fit than those that use pre-determined values even though the latter contain more route specific variations, such as by distance and purpose, than the former.

- The GC models that directly estimate the value of time imply mean GJT and fare elasticities that correspond well with the directly estimated GJT and fare elasticities. This though is not the case when pre-determined VoTs are used in constructing GC.

- The temporal and spatial variations in GJT and fare elasticities according to the proportions that they respectively form of GC as forced by the GC approach are not supported when explicitly tested in robust rail demand models based on large data sets.

- Examination of the review literature finds that the variations in the fare elasticities, time elasticities and values of time are not consistent with what would be implied by the GC approach.

- If the GC approach is to be used, then the directly estimated VoTs that best explain the balance between the demand impacts of time and fare changes are somewhat different to the pre-determined values.

Whilst directly estimated VoTs are clearly preferable within the GC approach, this will not always be possible for rail and, significantly, will hardly ever be the case for other modes. In addition, the evidence might even be indicating that official VoTs, based largely on Stated Preference evidence, are inaccurate.

In summary, the results raise serious concerns about the wisdom of the composite GC term in demand forecasting. Bruzelius (1981) queried whether we had "really shown that such models work?" We have shown that they do not work. To answer the question that is the title of this paper: GC in the form that it conventionally takes is not justified in a variety of rail markets. Given that the problems with GC apply pari passu to models based on Generalised Time also, Gunn's (1983) argument that "neither time nor cost is likely to provide a plausible unit system for conventional forecasting" further supports the view that the railway industry in Great Britain is entirely vindicated in its persistence with the GJTFare approach rather than going down the GC path.

Whilst the findings of this study are original, extensive and significant, much further research on this important subject is needed.

We have restricted our investigations to the standard constant elasticity models that dominate the analysis and forecasting practice based around aggregate models of the direct demand form. More flexible functions which allow the GC elasticity to vary can be estimated which also permit closer approximation of the GC, GJT-Fare, and the SC models through appropriate parameterisation of each model. For example, we might reject the strong elasticity variation forced by the conventional GC approach and here tested, but a more limited degree of variation might be supported using a more flexible functional form. Equally, interaction terms within the GJT-Fare and SC approaches can bestow elasticity properties similar to the GC approach. 
We have not here tested the weights used to construct GJT, and hence also GC, and whilst the SC approach demonstrates promise it makes more demands of the data and we face a challenge in recovering precise and plausible estimates of all parameters. Nor have we considered lagged behavioural responses, where there are inevitable additional challenges of interpretation if GC, GJT, fare and the SC variables exhibit different lags.

We have here focussed entirely on direct demand models based on secondary data. There is, of course, an 'alternative world' of behavioural modelling at a more disaggregate level based upon discrete choice models. These models do not use GC as an independent variable, although they could, and the default here is essentially the SC approach. An important point though is that such models in practical application often force considerable elasticity variation without empirical justification along the lines of the elasticity variation imposed by the GC models considered here. Nor have we considered the justification of using GC in network modelling.

There are therefore important further research issues to investigate, but our conclusions regarding the validity of the GC approach are profound and provide a long overdue start in a very much neglected area of analytical transport research.

Acknowledgements An earlier version of this work was presented at European Transport Conference 2008. This paper extends that work considerably. We are grateful for the comments of two anonymous referees.

Open Access This article is distributed under the terms of the Creative Commons Attribution 4.0 International License (http://creativecommons.org/licenses/by/4.0/), which permits unrestricted use, distribution, and reproduction in any medium, provided you give appropriate credit to the original author(s) and the source, provide a link to the Creative Commons license, and indicate if changes were made.

\section{Appendix: Key parameters of fixed effects and random effects models}

See Table 16. 


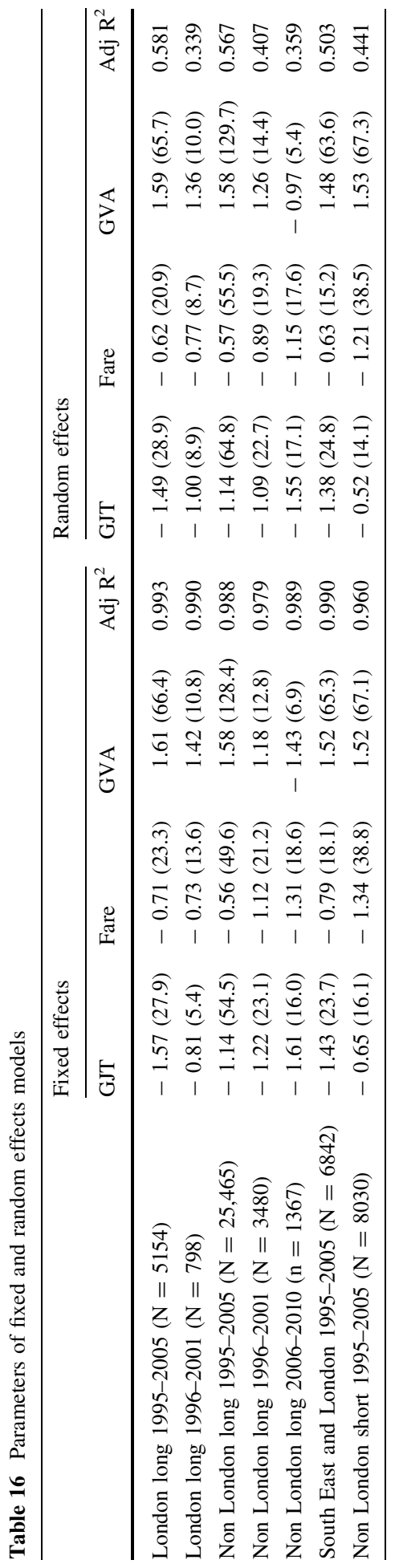




\section{References}

Abrantes, P.A.L., Wardman, M.: Meta-analysis of U.K. values of time: an update. Transp. Res. A 45(1), 1-17 (2011)

Association of Train Operating Companies.: Passenger Demand Forecasting Handbook. Edition 5.1, London (2013)

Balcombe, R., Mackett, R., Paulley, N., Preston, J., Titheridge, H., Wardman, M., White, P.: The demand for public transport: a practical guide. TRL Report 593, Crowthorne, Berks (2004)

Bruzelius, N.A.: Microeconomic theory and generalised cost. Transportation 10, 233-245 (1981)

Department for Transport.: Values of time and operating costs. Transport Analysis Guidance (TAG) Unit 3.5.6. www.webtag.org.uk (2006)

Goodwin, P.B.: On Grey's critique of generalised cost. Transportation 7, 281-295 (1978)

Goodwin, P.B.: A review of new demand elasticities with special reference to short and long run effects of price changes. J. Transp. Econ. Policy 26(2), 155-163 (1992)

Grey, A.: The generalised cost dilemma. Transportation 7, 261-280 (1978a)

Grey, A.: Has generalised cost any benefit? Transportation 7, 417-422 (1978b)

Gunn, H.F.: Generalised cost or generalised time? A note on the forecasting implications. J. Transp. Econ. Policy 17(1), 91-94 (1983)

Jones, I.: Urban Transport Appraisal. Macmillan, London (1977)

Leigh Fisher, ITS Leeds, RAND Europe and SYSTRA: Rail demand forecasting extension. Prepared for Department for Transport. available at https://www.gov.uk/government/uploads/system/uploads/ attachment_data/file/610059/phase2-rail-demand-forecasting-estimation-study.pdf (2016)

McIntosh, P.T., Quarmby, D.A.: Generalised costs and the estimation of movement costs and benefits in transport planning. MAU Note 179, Mathematical Advisory Note, Department of the Environment (1970)

SAS Institute.: SAS/ETS(R) 9.3 user's guide: the PANEL procedure. http://support.sas.com/documentation/ cdl/en/etsug/63939/HTML/default/viewer.htm\#etsug_panel_sect004.htm (2011). Accessed 23 May 2017

Searle, G.: Generalised cost: fool's gold or useful currency? Transportation 7, 297-299 (1978)

Transport Research Laboratory (TRL), Centre for Transport Studies University College London, Transport Studies Unit University of Oxford, Institute for Transport Studies University of Leeds, Transport Studies Group University of Westminster.: Demand for public transport: A practical guide. TRL Report TRL593, Crowthorne, Berkshire (2004)

TRRL.: The demand for public transport. Report of the International Collaborative Study of the Factors Affecting Public Transport Patronage. Crowthorne, Berks (1980)

Tyler, J., Hassard, R.: Gravity/elasticity models for the planning of the inter urban rail passenger business. In: Proceedings of Seminar G, PTRC Summer Annual Meeting, Warwick (1973)

Wardman, M.: Forecasting the impact of service quality changes on the demand for inter urban rail travel. J. Transp. Econ. Policy 28(3), 287-306 (1994)

Wardman, M.: Price elasticities of surface travel demand: a meta-analysis of UK evidence. J. Transp. Econ. Policy 48(3), 367-384 (2014)

Wardman, M.: Review and meta-analysis of U.K. time elasticities of travel demand. Transportation 39(3), 465-490 (2012)

Wardman, M., Dargay, J.M.: External factors data extension and modelling. Prepared for Department for Transport, Institute for Transport Studies, University of Leeds (2007)

Wardman, M., Whelan, G.: Estimating the effects of service quality changes on the demand for rail travel. Paper presented at AET European Transport Conference (2004)

Wheat, P., Wardman, M.: Effects of timetable related service quality on rail demand. Transp. Res. A 95, 96-108 (2017)

Wilson, A.: The use of entropy maximising models. J. Transp. Econ. Policy 3(1), 108-126 (1969)

Mark Wardman is Technical Director at SYSTRA and Visiting Professor at the Institute for Transport Studies, University of Leeds. Mark has been involved in transport research for over 30 years, during which time he has conducted and published many studies into the demand for rail travel using both aggregate econometric and discrete choice modelling techniques. A particular interest has been the functional form of travel demand models and the consistency of demand parameters obtained from different methods. His research has impacted significantly on the demand forecasting methods and parameters that are widely used in the railway industry in Great Britain. 
Jeremy Toner is Senior Lecturer in Transport Economics at the Institute for Transport Studies, University of Leeds. He has 25 years' experience of research in the public transport market, with a particular interest in demand elasticities and the relationship between different modes, along with interests in market structure and competition. He has also worked extensively on making the most of limited data or information in conjunction with economic theory in order to enhance the demand models used by public transport operators and by governments. 